\title{
Mortality Profile of the Non-Hispanic American Indian or Alaska Native Population, 2019
}

by Elizabeth Arias, Ph.D., Jiaquan Xu, M.D., Sally Curtin, M.A., Brigham Bastian, B.S., and

Betzaida Tejada-Vera, M.S., Division of Vital Statistics

\section{Abstract}

Objectives-This report presents a mortality profile of the U.S. non-Hispanic American Indian or Alaska Native (AIAN) population for 2019. Standard mortality statistics, adjusted for race and Hispanic-origin misclassification on death certificates, are provided along with comparisons with the three major U.S. populations: non-Hispanic white, non-Hispanic black, and Hispanic.

Methods - The data used to produce the mortality statistics shown in this report include final mortality data for 2019; July 1 , 2019, population estimates based on the 2010 decennial census; the 2018 and 2019 linked birth/infant death data files; and a data set consisting of 2010 decennial census AIAN records linked to mortality data. Age-specific and age-adjusted death rates, leading causes of death, and life expectancy estimates are adjusted for race and Hispanic-origin misclassification using adjustment factors produced from the census-mortality-linked data set.

Results-After adjusting for misclassification, the non-Hispanic AIAN population experienced substantially higher mortality than non-Hispanic white, non-Hispanic black, and Hispanic populations in the United States. Non-Hispanic AIAN persons experienced greater all-cause mortality, higher agespecific death rates at most ages but particularly at younger ages, and higher mortality for most of the top leading causes of death. They also had the lowest life expectancy at birth (71.8) compared with the non-Hispanic white (78.8), non-Hispanic black (74.8), and Hispanic (81.9) populations.

Keywords: cause of death $\bullet$ life expectancy $\bullet$ disparities $\bullet$ race $\bullet$ Hispanic origin $\bullet$ National Vital Statistics System

\section{Introduction}

To date, there has been a dearth of published national mortality statistics for the American Indian or Alaska Native (AIAN) population due to poor data quality among this population $(1,2)$. Misclassification of race and ethnicity on U.S. death certificates is the primary source of data problems, although census population estimates also present challenges to the estimation of reliable mortality statistics for the AIAN population $(3,4)$. Previous research has consistently shown that $30 \%$ or more of individuals who self-identify as non-Hispanic AIAN are misclassified to a different race and ethnicity group on death certificates (5-7). The main effect of race and Hispanicorigin misclassification on death certificates is substantial underestimation of mortality for this population.

This report presents a mortality profile of the U.S. non-Hispanic AIAN population for 2019. Standard mortality statistics, including age-specific and age-adjusted death rates, leading causes of death, and life expectancy estimates are provided along with comparisons with the three major U.S. populations: non-Hispanic white, non-Hispanic black, and Hispanic. The mortality statistics presented in this report for the non-Hispanic AIAN population are adjusted for misclassification of race and Hispanic origin on death certificates with classification ratios (adjustment factors) produced from a linkage of records of AIAN respondents to the 2010 decennial census with National Vital Statistics System (NVSS) mortality data (see Technical Notes for details).

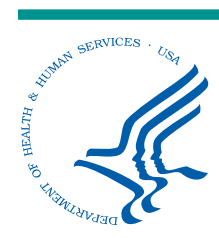

U.S. DEPARTMENT OF HEALTH AND HUMAN SERVICES 


\section{Background}

\section{Mortality statistics for the U.S. AIAN population}

Mortality statistics for the AIAN population have been included in data files produced and published from the U.S. NVSS beginning with the first publication of vital statistics for the U.S. registration areas for 1900 (8). While the earlier race categories included "Indian," published mortality statistics for this population were limited to death counts by state and territory, age, and sex (8). In ensuing years, detailed statistics other than aggregate death counts for the AIAN population were included in the broad categories "colored," "non-white," or "other races," combined with those for black, Chinese-, and Japanese-origin populations. More detailed mortality statistics, such as death rates by age and sex for the AIAN population, were first presented for data year 1960 (9). Between 1961 and 1993, detailed mortality statistics for the AIAN population were again grouped within the broad categories "non-white" or "other race." Detailed mortality statistics for the AIAN population separately were published again in 1994 and have since been published annually (10). Published detailed mortality statistics include sexage-specific death counts and death rates, and leading causes of death. National life expectancy estimates, published for the white and black populations regularly since 1900 , have not been produced for the entire non-Hispanic AIAN population until this report (11).

An important reason for the sparseness or absence of detailed mortality statistics for the U.S. AIAN population has been the misclassification of race and ethnicity on death certificates that has historically affected AIAN mortality data (1). Classification of race and Hispanic origin on death certificates is usually the responsibility of funeral directors who must gather the information from next of kin or rely on observation (6). This may be especially problematic for populations with large proportions of multiple-race persons, such as the AIAN population (6). The first study to evaluate race classification on death certificates, the 1960 Census-Death Certificate Matched Study, found that $21 \%$ of self-identified AIAN were incorrectly classified on death certificates (12). Four subsequent studies, covering deaths for years 1979-2011, similarly found high rates of racial misclassification for the AIAN population. Based on a linkage of Current Population Surveys (CPS) to NVSS mortality data (National Longitudinal Mortality Study), net misclassification rates between CPS self-identification and death certificate classification ranged between $30 \%$ and $45 \%(1,5-6)$. A study based on the AIAN Mortality Database (AMD), a linkage of Indian Health Service (IHS) patient registration records with NVSS mortality data for years 1990-2009, revealed that misclassification was lower in areas with higher concentrations of AIAN populations than in areas with lower concentrations, although still substantial; 20\% compared with $82 \%$ (2).

To date, the most comprehensive and reliable mortality profile of the U.S. AIAN population is based on the AMD (3). A mortality profile of the non-Hispanic AIAN population in IHS Contract Health Service Delivery Area or Tribal Service Delivery Area counties (CHSDA counties) revealed vast disparities in all-cause and cause-specific mortality between the non-Hispanic AIAN and the non-Hispanic white populations (3). Adjusted for race and Hispanic-origin misclassification on death certificates, the non-Hispanic AIAN population experienced age-adjusted death rates that were $46 \%$ greater than those of the non-Hispanic white population in CHSDA counties during the period 2000-2009 (3). Mortality disparities were most evident in younger age groups. Non-Hispanic AIAN age group 25 to 44 years experienced allcause death rates that were nearly three times higher than those of non-Hispanic white persons (3). Non-Hispanic AIAN males experienced considerably higher death rates for all 15 leading causes of death than the non-Hispanic white male population, with cause-specific rate ratios ranging from 1.09 for deaths due to Chronic lower respiratory diseases to 4.85 for deaths due to homicide. Similarly, with one exception (Alzheimer disease deaths), non-Hispanic AIAN females experienced higher death rates for the top 15 leading causes of death than non-Hispanic white persons, with rate ratios ranging from 1.03 for Chronic lower respiratory diseases to 5.36 for deaths due to Chronic liver disease and cirrhosis (3). Life expectancy at birth was 71.1, 68.0, and 74.3 for non-Hispanic AIAN total, male, and female populations, respectively, in CHSDA counties during the period 2007-2009 (4). By comparison, life expectancy at birth was $78.4,76.0$, and 80.7 years for non-Hispanic white total, male, and female populations, respectively, in 2008 (4).

An important limitation of the AMD-based study is that it pertains only to $64 \%$ of the non-Hispanic AIAN population; the segment that resides in the 637 CHSDA counties (3). As a result, the study omits AIAN persons who are not members of federally recognized tribes and therefore not eligible for IHS services. It excludes many AIAN persons living in urban areas that are not part of a CHSDA county (3). The current study expands upon the AMD-based study because it includes all U.S. non-Hispanic AIAN deaths, adjusted for misclassification, in 2019. As with the AMD study, the current study omits a small but important segment of the AIAN population (Hispanic AIAN). Population estimates, both intercensal and postcensal, based on the 2010 decennial census overestimate the Hispanic AIAN population as a result of the algorithm the Census Bureau used to impute responses of "some other race" to one, or a combination, of the five approved Office of Management and Budget race categories $(3,4)$.

\section{Data and Methods}

The data used to produce the mortality statistics shown in this report include final numbers of deaths for the year 2019; July 1, 2019 population estimates based on the 2010 decennial census; and the 2018 and 2019 linked birth/infant death data files. An extract of the Census Bureau's 2010 decennial Census Edited File (CEF)-Census Unedited File (CUF) Match File containing records for persons classified as AIAN alone or in combination with another race was linked to NVSS death certificates for years 2010-2011 to produce classification ratios (correction factors). These ratios were used to correct for race and Hispanic-origin misclassification on death certificates for the non-Hispanic AIAN population (see Technical Notes for detailed description of data and methodology). 
The non-Hispanic AIAN mortality statistics presented in this report have been adjusted for race and Hispanic-origin misclassification on death certificates using classification ratios and include number of deaths, age-specific and age-adjusted death rates, leading causes of death, and life expectancy estimates. The methodology used to estimate the classification ratios is the same as that developed for a previous study of racial and ethnic misclassification on death certificates based on the National Longitudinal Mortality Study $(1,6)$. The classification ratios presented in this report consist of the ratio of CEF-CUF Match AIAN extract file non-Hispanic AIAN counts to death certificate non-Hispanic AIAN counts for the sample of decedents in the CEF-CUF Match AIAN-Mortality-linked data file. Classification ratios were estimated by decedent's sex, age, and cause of death. Differences in death rates between population groups are shown using death rate ratios. Age-specific and ageadjusted death rates for non-Hispanic white, non-Hispanic black, and Hispanic populations were not adjusted for misclassification. Previous studies have shown that misclassification for the former two populations is negligible with a classification ratio of 0.9995 for the non-Hispanic white population and 1.0047 for the non-Hispanic black population (11). Misclassification for the Hispanic population was greater than that of the other two groups with a classification ratio of 1.0329 (11). The methodology used to estimate life tables for the non-Hispanic AIAN population is the same as that used for the non-Hispanic AIAN population living in CHSDA counties and based on the AMD (4) (see Technical Notes for a detailed description of life table methods). The methods used to produce the life tables for the three other population groups are those used to produce the annual U.S. life tables (11).

\section{Results}

In agreement with previous evaluations of race and Hispanic-origin classification on death certificates, this study found that $34 \%$ (classification ratio of 1.3354) of non-Hispanic AIAN decedents were classified as a different race on death certificates, with $35 \%(1.3488)$ of males and $32 \%(1.3197)$ of females misclassified (1,2,5-7). Approximately $28 \%$ of selfidentified non-Hispanic AIAN decedents were misclassified as non-Hispanic white on death certificates, followed by $4 \%$ misclassified as non-Hispanic black, and less than $1 \%$ misclassified as non-Hispanic Asian or Pacific Islander. Race and Hispanic-origin misclassification on death certificates varied by sex, age, and cause of death. The mortality statistics presented in the remainder of this report for the non-Hispanic AIAN population are adjusted for misclassification on death certificates using the classification ratios produced from the CEF-CUF Match AIANMortality data file (see Technical Notes for detailed description of statistical methods).

\section{Deaths and age-adjusted death rates}

Deaths among non-Hispanic AIAN persons in the United States in 2019, after adjusting for race and Hispanic-origin misclassification, numbered 24,113 for both sexes; 13,127 to males and 10,987 to females (Table 1 ). The age-adjusted death rate for the non-Hispanic AIAN population was $1,036.7$ per 100,000 U.S. standard population (Figure 1 and Table 1). The non-Hispanic AIAN rate ratios (rate for non-Hispanic AIAN divided by the rates for other groups) were 1.40, 1.17, and 1.98 for the non-Hispanic white, non-Hispanic black, and Hispanic populations, respectively (see Tables I- 1 and I-2 for rates for non-Hispanic white, non-Hispanic black, and Hispanic populations). The age-adjusted death rate for non-Hispanic AIAN males was $1,209.6$ with rate ratios of $1.39,1.11$, and 1.91 for non-Hispanic white, non-Hispanic black, and Hispanic males, respectively. For non-Hispanic AIAN females, the age-adjusted death rate was 880.6 with rate ratios of $1.40,1.21$, and 2.04 for non-Hispanic white, non-Hispanic black, and Hispanic females, respectively.

\section{Age-specific death rates}

The age-specific mortality profile of the non-Hispanic AIAN population in 2019 follows the expected pattern where mortality is relatively high at birth, reaches its lowest point for age group 5-14 years, and then increases steadily with age (Figure 2 and Table 1). Non-Hispanic AIAN males experienced higher mortality than female persons at all ages, except for age group 85 and over. The age-specific death rate for males $(11,350.2)$ was $96 \%$ of that of females $(11,838.8)$ for age group 85 and over and ranged from 6\% (726.5 compared with 682.8 for age group under 1) to $79 \%$ (435.3 compared with 242.8 for age group 25-34) higher than those of females in other age groups under 85 .

The non-Hispanic AIAN population had higher age-specific death rates than non-Hispanic white, non-Hispanic black, and Hispanic populations at most ages (Figures $3 a-3 c$, Table 1, and Table I-1). The largest differences between the non-Hispanic AIAN and the other three populations for both males and females were for age groups $1-4,25-34,35-44$, and $45-54$, where ratios of non-Hispanic AIAN age-specific death rates to those of the other three populations ranged from a low of 1.61 to a high of 4.01 (Figure 3a). For age group under 1, death rates for non-Hispanic AIAN males (726.5) and females (682.8) were $43 \%$ $(1,266.1)$ and $37 \%(1,080.0)$ lower than those of non-Hispanic black persons (Figures $3 \mathrm{~b}$ and $3 \mathrm{c}$ ). For age group 85 and over, death rates for non-Hispanic AIAN males $(11,350.2)$ were $75 \%$ and $87 \%$ that of non-Hispanic white $(15,123.0)$ and non-Hispanic black $(13,094.9)$ persons, respectively. The non-Hispanic AIAN female death rate $(11,838.8)$ for age group 85 and over was $88 \%$ that of non-Hispanic white females $(13,464.4)$.

\section{Leading causes of death}

In 2019, the 15 leading causes of death for the non-Hispanic AIAN population accounted for $79.0 \%$ of all deaths occurring to this population (Table 2). Adjustment for misclassification did not change the content of the 15 leading causes list but did affect the ranking order of a few causes. The first two leading causes of death, Diseases of heart (heart disease) and Malignant neoplasms (cancer), accounted for $36.6 \%$ of all deaths. Accidents (unintentional injuries) was the 3rd leading cause of death, accounting for $10.6 \%$ of all deaths. Chronic liver disease 
Figure 1. Age-adjusted death rates, by race and Hispanic origin and sex: United States, 2019

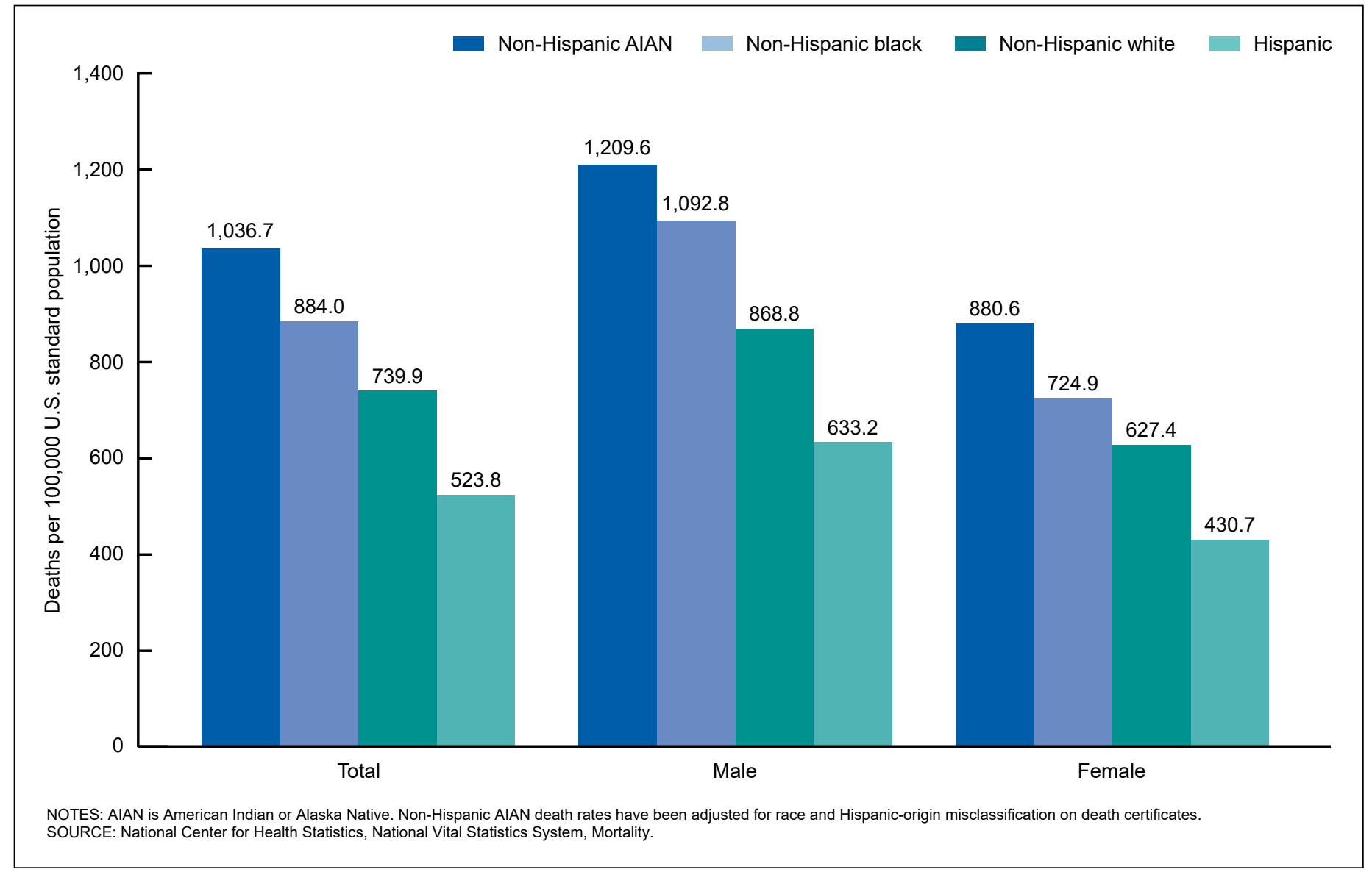

Figure 2. Age pattern of mortality for the non-Hispanic AIAN population, by sex: United States, 2019

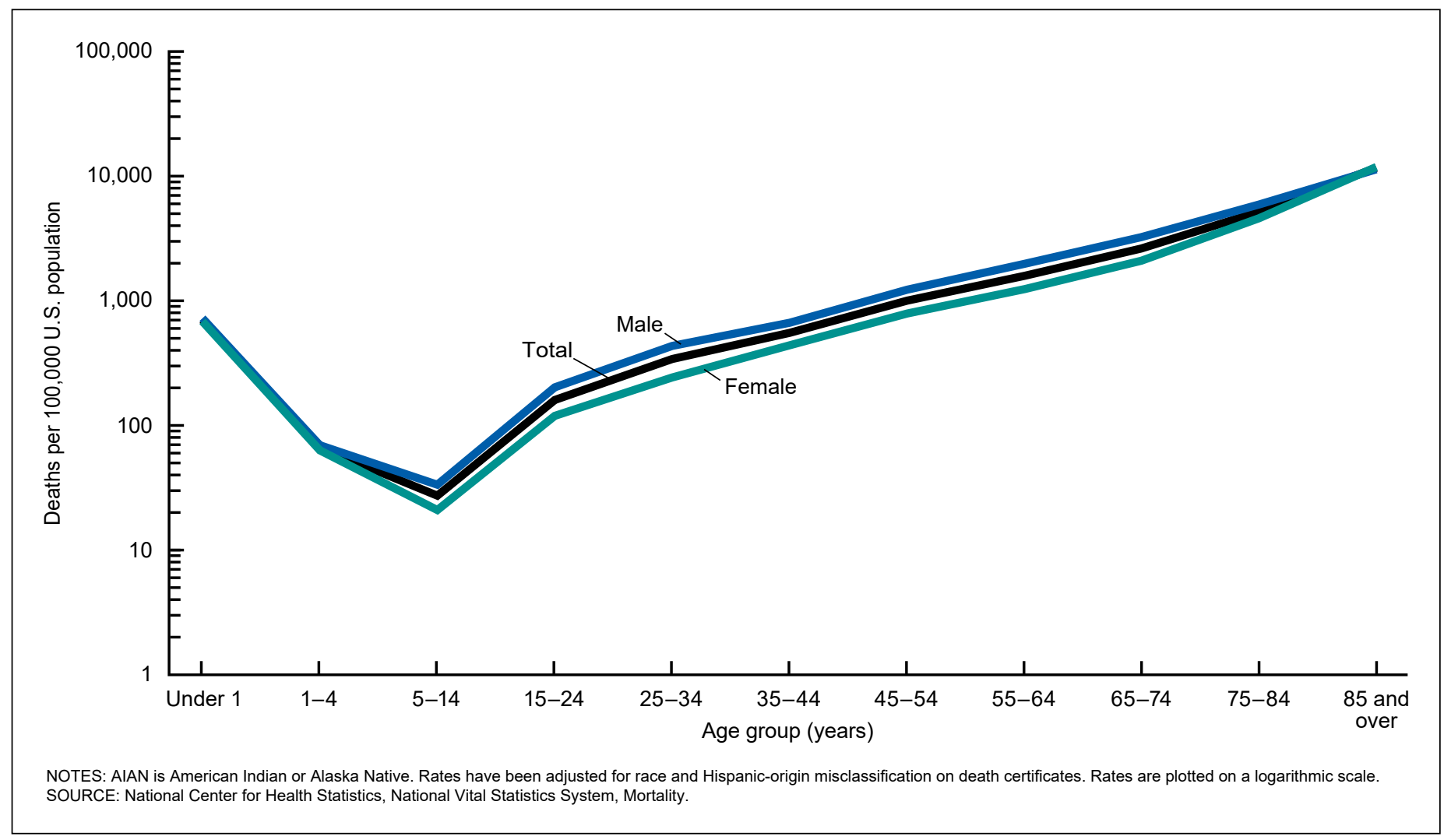


Figure 3. Rate ratios of non-Hispanic AIAN to Hispanic, non-Hispanic white, and non-Hispanic black populations, by age and sex: United States, 2019

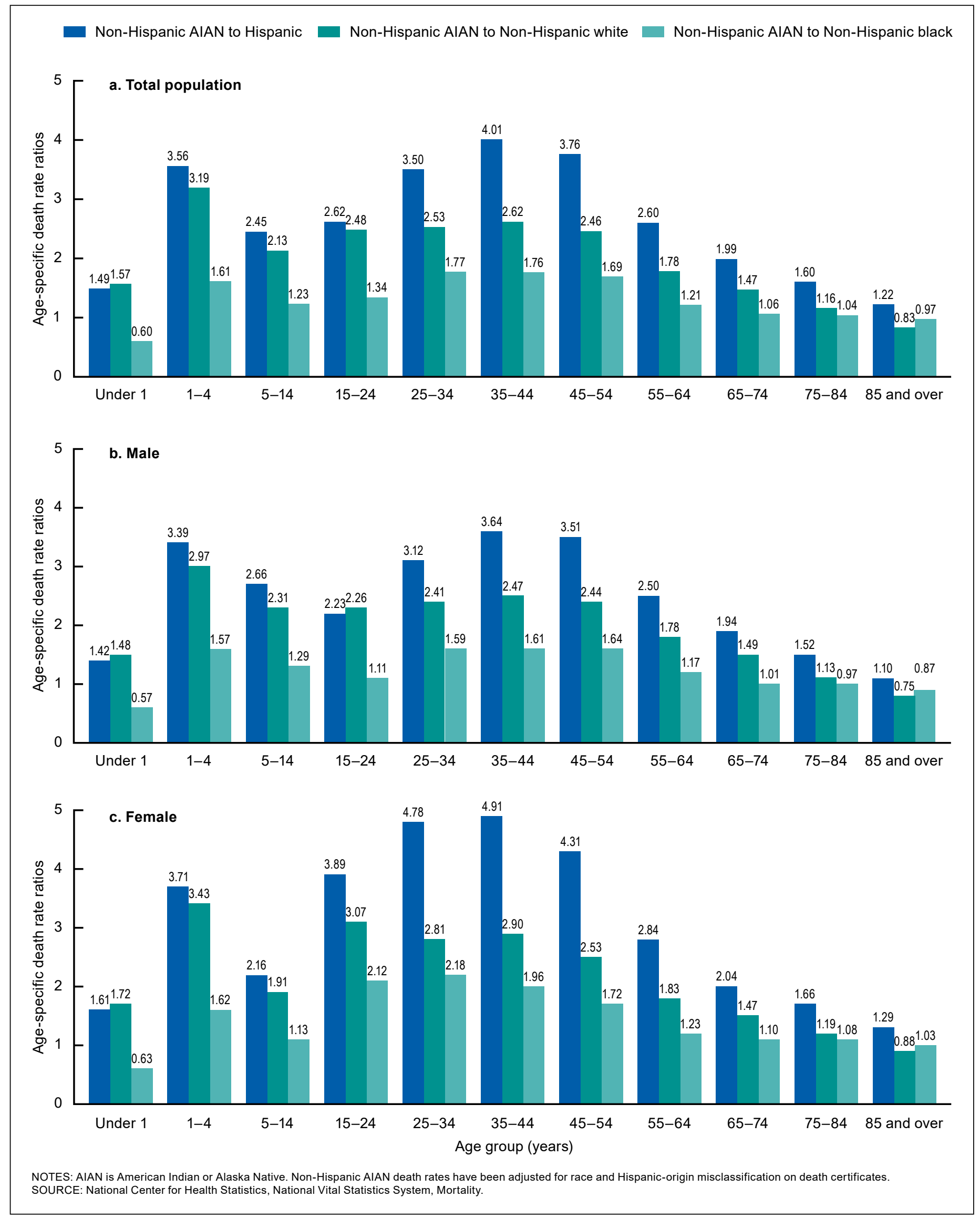


and cirrhosis was the 4th leading cause of death $(5.2 \%$ of all deaths). The 5th, 6th, and 7th leading causes of death, Chronic lower respiratory diseases, Diabetes mellitus (diabetes), and Cerebrovascular diseases (stroke), accounted for $13.7 \%$ of all deaths. Intentional self-harm (suicide), the 8th leading cause of death, accounted for $2.9 \%$ of all deaths. The 9th, 10th, 11th, and 12th leading causes, Nephritis, nephrotic syndrome and nephrosis (kidney disease), Influenza and pneumonia, Alzheimer disease, and Septicemia, accounted for $7.0 \%$ of all deaths. Assault (homicide), the 13th leading cause, accounted for $1.4 \%$ of all deaths.

Non-Hispanic AIAN males and females shared the same 15 leading causes, but the ranking order and age-adjusted death rates differed. For example, heart disease was the leading cause of death for males and accounted for $21 \%$ of all male deaths; the age-adjusted death rate for heart disease among males was 257.7 deaths per 100,000 U.S. standard population (Figure 4). In contrast, cancer was the leading cause for females and represented $17.9 \%$ of all female deaths; the age-adjusted death rate for cancer among females was 149.5. Of special note are differences in sex-specific rankings and death rates for select causes. For example, suicide was the 7 th leading cause ( $4 \%$ of all deaths) for males and the 11th leading cause (1.5\%) for females. Age-adjusted suicide death rates were 45.6 for males and 14.1 and females. Homicide was the 9th leading cause $(1.8 \%)$ for males but the 14 th leading cause $(0.8 \%)$ for females. Age-adjusted homicide death rates were 19.6 for males and 7.3 for females.

The non-Hispanic AIAN population experienced substantially greater cause-specific mortality for 13 and 14 of the 15 leading causes of death than the Hispanic and non-Hispanic white populations, respectively (Table 2, Figure 5 , and Table I-2). When compared with the Hispanic population, the age-adjusted death rate for suicide for the non-Hispanic AIAN population was four times greater (rate ratio of 4.01 [29.3:7.3]), the largest difference of all the leading causes. When compared with the non-Hispanic white population, the death rate for homicide was five times higher (rate ratio of 5.00 [29.3:17.7]) for non-Hispanic AIAN persons, the greatest difference in rates for the leading causes. The age-adjusted death rate for liver disease for the non-Hispanic AIAN population was approximately four times the rate for non-Hispanic white persons (rate ratio of 4.06 [49.7:11.9]) and more than three times the rate for Hispanic persons (rate ratio of 3.43 [49.7:14.6]). The age-adjusted death rate for the top leading cause of death, heart disease, for non-Hispanic AIAN (198.9) was $20.2 \%$ higher (rate ratio of 1.20) than the rate for the non-Hispanic white population (166.4) and $86.0 \%$ higher (rate

\section{Figure 4. Percent distribution for the 15 leading causes of death for non-Hispanic AIAN males and females: United States, 2019}

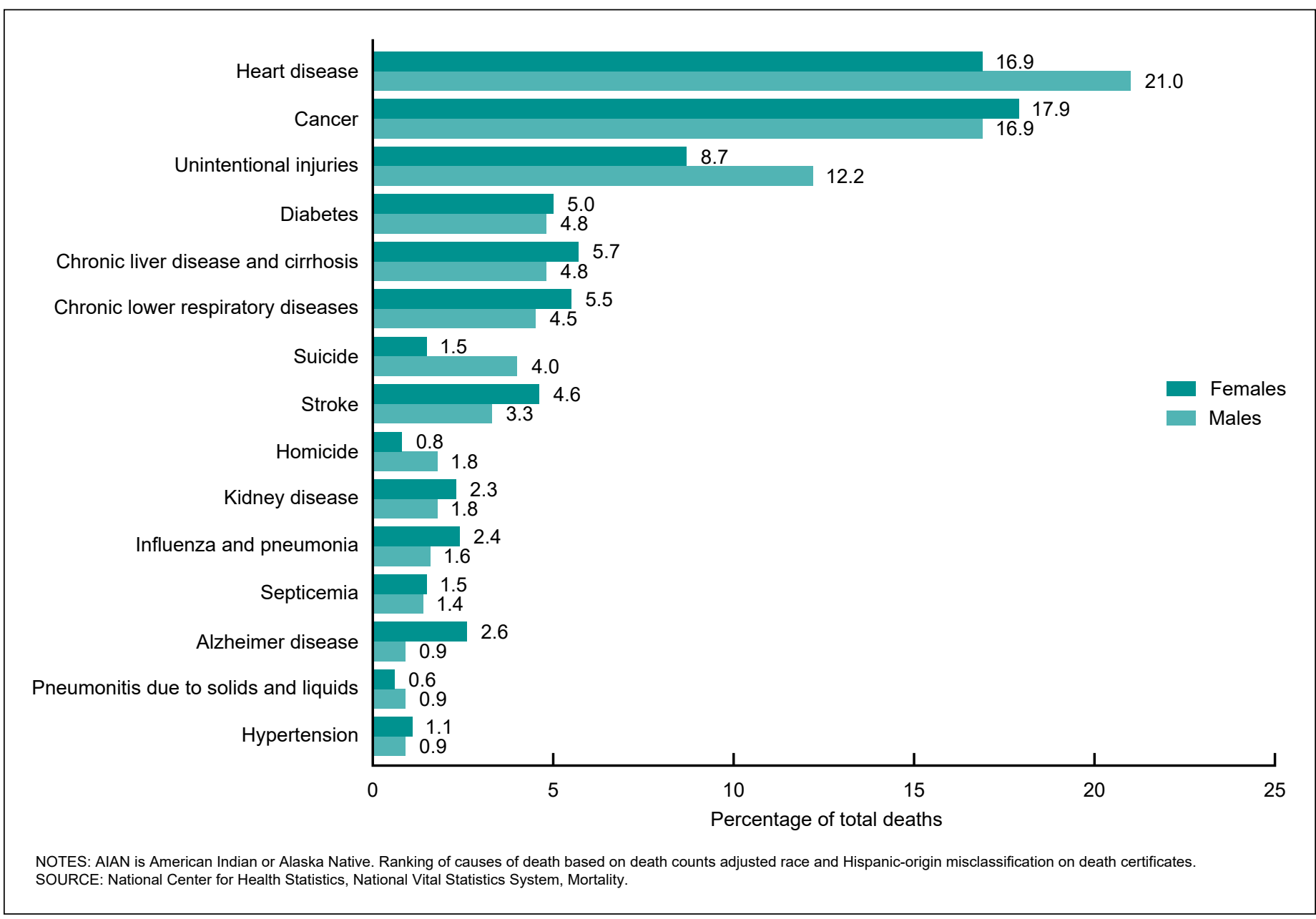


Figure 5. Age-adjusted death rate ratios by 15 leading causes of death for the non-Hispanic AIAN to Hispanic, non-Hispanic white, and non-Hispanic black populations: United States, 2019

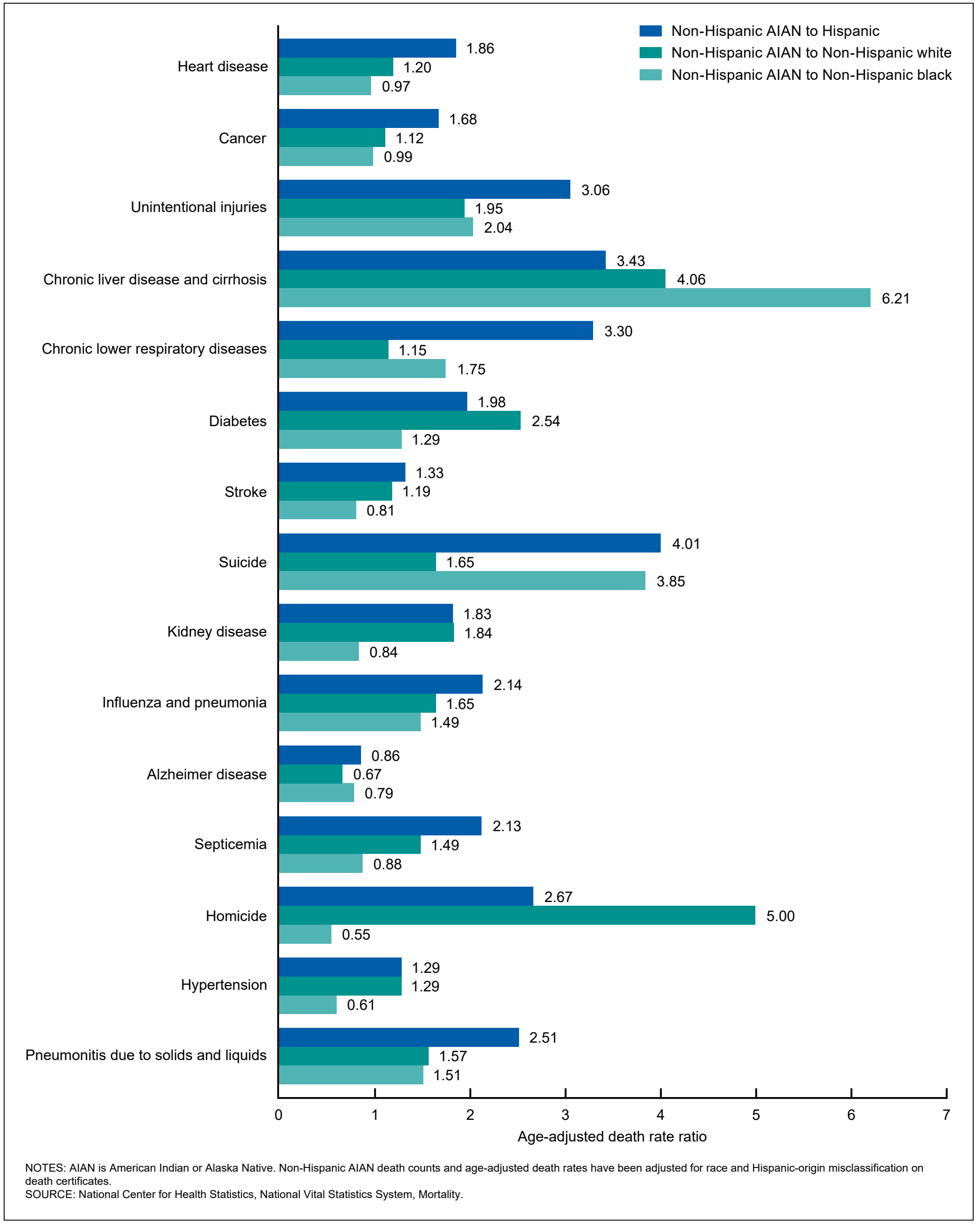


ratio of 1.86) than the rate for the Hispanic population (111.3). The age-adjusted death rate for liver disease for the non-Hispanic AIAN population was more than six times (rate ratio of 6.21 [49.7:7.7]) that for the non-Hispanic black population, the greatest difference among the leading causes. However, rates for the two top leading causes, heart disease and cancer, were very similar for non-Hispanic AIAN and non-Hispanic black persons (rate ratios of 0.97 [198.9:208.6] and 0.99 [172.2:173.1], respectively). Rates for 7 of the 15 leading causes were lower for non-Hispanic AIAN than non-Hispanic black persons with a homicide rate of nearly one-half (rate ratio of 0.55 [13.5:23.7]). The age-adjusted death rates by sex followed a similar pattern.

\section{Life expectancy}

In 2019, life expectancy at birth was 71.8 years for the total non-Hispanic AIAN population (Table and Table 3). By comparison, life expectancy at birth was 81.9 years for the Hispanic population, 78.8 years for the non-Hispanic white population, and 74.8 years for the non-Hispanic black population. The non-Hispanic AIAN population could expect to live 10.1 fewer years than the Hispanic population, 7 fewer years than the non-Hispanic white population, and 3 fewer years than the non-Hispanic black population.

Among the eight Hispanic origin-race-sex populations (Figure 6, Tables 4-5), non-Hispanic AIAN males had the lowest life expectancy at birth (68.6 years), followed by non-Hispanic black males (71.3), non-Hispanic AIAN females (75.0), non-Hispanic white males (76.3), non-Hispanic black females (78.1), Hispanic males (79.1), non-Hispanic white females (81.3), and Hispanic females (84.4). Life expectancy at birth for non-Hispanic AIAN males was 10.5 years lower than that of Hispanic males, 7.7 years lower than that of non-Hispanic white males, and 2.7 years lower than that of non-Hispanic black males. Non-Hispanic AIAN females experienced a disadvantage of 9.4 years relative to Hispanic females, 6.3 years relative to non-Hispanic white females, and 3.1 years relative to non-Hispanic black females.

In comparison with all three other groups, the non-Hispanic AIAN population experienced lower life expectancy throughout most of the age span (Table). The disadvantage is greatest at the youngest ages diminishing with increasing age and converting to an advantage at the oldest ages. The crossover happens earlier relative to the non-Hispanic black population, for age group 60-64 for males and age group 75-79 for females. It occurs at older ages relative to the non-Hispanic white (age group 80-84 for both males and females) and Hispanic (age group 90-94 for both males and females) populations.

\section{Discussion and Summary}

This report presented the first ever comprehensive mortality profile of the entire U.S. non-Hispanic AIAN population, adjusted for misclassification. It reveals that this population experiences substantially higher mortality than non-Hispanic white, non-Hispanic black, and Hispanic populations in the United States. Non-Hispanic AIAN persons experience greater all-cause mortality, higher age-specific death rates at most ages but particularly at younger ages, and higher mortality for most of the top leading causes of death. They experience mortality from chronic liver disease, suicide, and unintentional injuries that is considerably greater than that experienced by the other race and Hispanic-origin populations. The non-Hispanic AIAN

Table. Life expectancy at selected ages, by race and Hispanic origin and sex: United States, 2019

\begin{tabular}{|c|c|c|c|c|c|c|c|c|c|c|c|c|}
\hline \multirow[b]{2}{*}{ Age } & \multicolumn{3}{|c|}{ Non-Hispanic AIAN } & \multicolumn{3}{|c|}{ Hispanic } & \multicolumn{3}{|c|}{ Non-Hispanic white } & \multicolumn{3}{|c|}{ Non-Hispanic black } \\
\hline & Total & Male & Female & Total & Male & Female & Total & Male & Female & Total & Male & Female \\
\hline$\ldots \ldots \ldots$ & 71.8 & 68.6 & 75.0 & 81.9 & 79.1 & 84.4 & 78.8 & 76.3 & 81.3 & 74.8 & 71.3 & 78.1 \\
\hline $1 \ldots \ldots \ldots \ldots$ & 71.3 & 68.2 & 74.5 & 81.3 & 78.5 & 83.8 & 78.1 & 75.7 & 80.6 & 74.6 & 71.1 & 77.9 \\
\hline $5 \ldots \ldots \ldots \ldots$ & 67.5 & 64.4 & 70.7 & 77.3 & 74.6 & 79.9 & 74.2 & 71.8 & 76.6 & 70.7 & 67.3 & 74.0 \\
\hline $10 \ldots \ldots \ldots \ldots$ & 62.6 & 59.5 & 65.8 & 72.4 & 69.6 & 74.9 & 69.2 & 66.8 & 71.7 & 65.8 & 62.3 & 69.1 \\
\hline $15 \ldots \ldots \ldots \ldots$ & 57.7 & 54.6 & 60.8 & 67.4 & 64.6 & 69.9 & 64.3 & 61.9 & 66.7 & 60.9 & 57.4 & 64.1 \\
\hline $20 \ldots \ldots \ldots \ldots$ & 53.0 & 50.0 & 56.1 & 62.5 & 59.8 & 65.0 & 59.4 & 57.1 & 61.8 & 56.1 & 52.8 & 59.2 \\
\hline $25 \ldots \ldots \ldots \ldots$ & 48.5 & 45.6 & 51.5 & 57.8 & 55.1 & 60.2 & 54.7 & 52.4 & 56.9 & 51.5 & 48.4 & 54.5 \\
\hline $30 \ldots \ldots \ldots \ldots$ & 44.1 & 41.4 & 46.9 & 53.0 & 50.5 & 55.3 & 50.0 & 47.8 & 52.1 & 47.0 & 43.9 & 49.7 \\
\hline $35 \ldots \ldots \ldots \ldots$ & 40.0 & 37.4 & 42.6 & 48.3 & 45.9 & 50.4 & 45.3 & 43.2 & 47.4 & 42.4 & 39.6 & 45.0 \\
\hline $40 \ldots \ldots \ldots \ldots$ & 36.0 & 33.5 & 38.4 & 43.6 & 41.3 & 45.6 & 40.7 & 38.7 & 42.7 & 38.0 & 35.2 & 40.4 \\
\hline $45 \ldots \ldots \ldots \ldots$ & 32.0 & 29.7 & 34.3 & 38.9 & 36.7 & 40.9 & 36.2 & 34.3 & 38.0 & 33.6 & 31.0 & 35.9 \\
\hline $50 \ldots \ldots \ldots \ldots$ & 28.3 & 26.1 & 30.4 & 34.4 & 32.2 & 36.2 & 31.7 & 29.9 & 33.5 & 29.4 & 26.9 & 31.5 \\
\hline $55 \ldots \ldots \ldots \ldots$ & 24.8 & 22.8 & 26.7 & 29.9 & 27.9 & 31.6 & 27.4 & 25.7 & 29.0 & 25.3 & 23.0 & 27.3 \\
\hline $60 \ldots \ldots \ldots \ldots$ & 21.4 & 19.7 & 23.0 & 25.6 & 23.8 & 27.1 & 23.4 & 21.8 & 24.8 & 21.6 & 19.5 & 23.4 \\
\hline $65 \ldots \ldots \ldots \ldots$ & 18.2 & 16.7 & 19.5 & 21.6 & 19.9 & 22.9 & 19.5 & 18.1 & 20.7 & 18.2 & 16.3 & 19.7 \\
\hline $70 \ldots \ldots \ldots \ldots$ & 15.2 & 14.0 & 16.1 & 17.7 & 16.2 & 18.7 & 15.8 & 14.6 & 16.7 & 15.0 & 13.4 & 16.2 \\
\hline $75 \ldots \ldots \ldots \ldots$ & 12.2 & 11.3 & 13.0 & 14.0 & 12.8 & 14.8 & 12.3 & 11.3 & 13.1 & 12.0 & 10.7 & 12.9 \\
\hline $80 \ldots \ldots \ldots \ldots$ & 9.6 & 8.8 & 10.2 & 10.7 & 9.6 & 11.2 & 9.2 & 8.4 & 9.8 & 9.3 & 8.2 & 9.9 \\
\hline $85 \ldots \ldots \ldots \ldots$ & 7.4 & 6.7 & 7.8 & 7.8 & 6.9 & 8.1 & 6.6 & 6.0 & 7.0 & 6.9 & 6.2 & 7.3 \\
\hline $90 \ldots \ldots \ldots \ldots$ & 5.6 & 5.1 & 5.8 & 5.5 & 4.8 & 5.6 & 4.5 & 4.0 & 4.8 & 5.1 & 4.6 & 5.3 \\
\hline $95 \ldots \ldots \ldots \ldots$ & 4.2 & 3.8 & 4.3 & 3.8 & 3.3 & 3.8 & 3.1 & 2.7 & 3.2 & 3.7 & 3.4 & 3.8 \\
\hline $100 \ldots \ldots \ldots \ldots$ & 3.3 & 3.0 & 3.3 & 2.7 & 2.3 & 2.7 & 2.2 & 2.0 & 2.2 & 2.8 & 2.6 & 2.8 \\
\hline
\end{tabular}

NOTE: AIAN is American Indian or Alaska Native.

SOURCE: National Center for Health Statistics, National Vital Statistics System, Mortality. 
Figure 6. Life expectancy at birth, by race and Hispanic origin and sex: United States, 2019

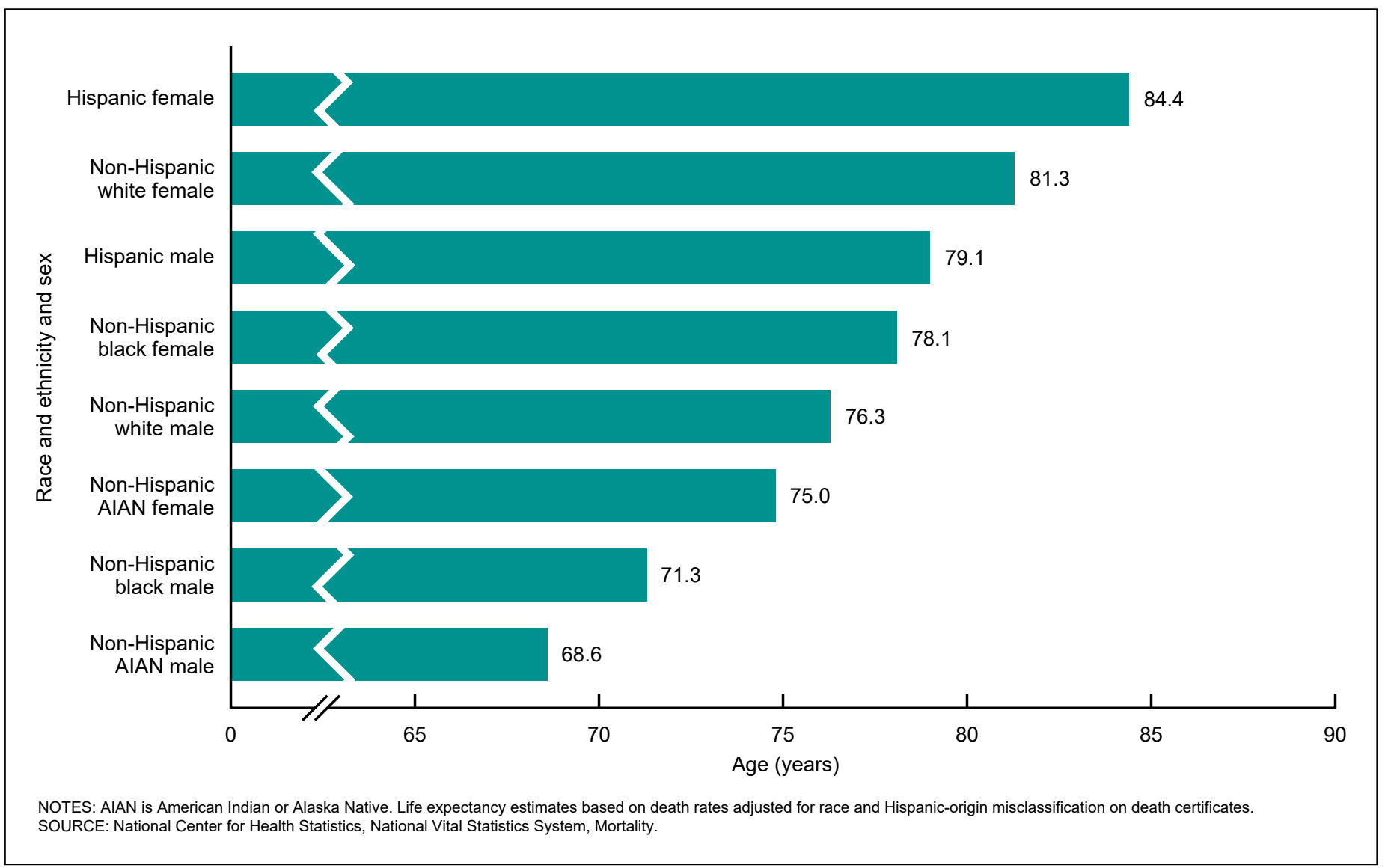

population has the lowest life expectancy at birth compared with the non-Hispanic white, non-Hispanic black, and Hispanic populations, with disadvantages ranging from 3.0 (non-Hispanic black) to 10.1 years (Hispanic).

The results of this study are consistent with those based on the AMD, even though the latter covered only $64 \%$ of the non-Hispanic AIAN population in the United States $(3,4,13)$. For example, one study based on the AMD found that non-Hispanic AIAN all-cause mortality was $46 \%$ greater than that of the non-Hispanic white population (3). This study found that it was $40 \%$ greater. The same study also found that mortality from causes such as unintentional injury, chronic liver disease, diabetes, and homicide were multiple times those of the majority of the population (3). Finally, life expectancy at birth estimates based on the AMD were only slightly higher than those presented in this report (71.8 compared with 71.1 for the total population, 68.6 compared with 68.0 for males, and 75.0 compared with 74.3 for females) (4).

The racial and ethnic crossover in life expectancy (mortality), described here for the oldest AIAN population, has been observed in the United States for decades mostly in comparisons of white and black mortality. It is defined as the convergence, intersection, and inversion of the age-specific mortality curves of two distinct race groups in a population, where one group experiences higher mortality throughout most of the lifespan up until a given advanced age and then experiences lower mortality throughout the remaining life span (15). There are two explanations for this phenomenon: data artifact and population selection. The data artifact explanation hypothesizes that the crossover is a function of poor data quality in the form of age misreporting at the oldest ages. The population selection explanation posits that, due to its disadvantaged status, one group experiences a higher mortality regime so that its frailest members succumb at younger ages, leaving the hardiest members to survive to the oldest ages. The advantaged population, on the other hand, experiences a more benign mortality regime and, as a result, frailer members survive to older ages where they tend to die sooner than disadvantaged persons and thus create the crossover effect (15). Both population selection and data artifact could be factors with the results for the non-Hispanic AIAN population shown in this report.

This study has important limitations. First, the results are based on adjusted data, not observed data. Although the classification ratios used to adjust the data are consistent with the findings of previous studies, they are not error free. The National Death Index (NDI) matching algorithm may have missed some true deaths (16). Census records that did not have the minimum required variables for matching were omitted from the records submitted to NDI. The census records submitted to NDI did not have social security numbers (SSN), an important matching variable, and the match relied on names, birth dates, sex, race, and state of residence. The lack of SSN could potentially lower the match rates and may explain some of the differences between the AMD and current non-Hispanic AIAN life tables $(4,17)$. Second, a small segment of the AIAN population, Hispanic AIAN 
persons, were omitted from the study. This could possibly bias the overall findings of the study. Hispanic persons have generally been shown to have lower mortality than non-Hispanic persons, so the omission may lead to the appearance of higher mortality among the AIAN population overall. However, the problem with population counts for this group warrants exclusion.

\section{References}

1. Arias E, Heron M, Hakes JK. The validity of race and Hispanic origin reporting on death certificates in the United States: An update. Vital Health Stat 2(172). Hyattsville, MD: National Center for Health Statistics. 2016. Available from: https://www.cdc.gov/ nchs/data/series/sr_02/sr02_172.pdf.

2. Jim MA, Arias E, Seneca DS, Hoopes MJ, Jim CC, Johnson NJ, Wiggins CL. Racial misclassification of American Indians and Alaska Natives by Indian Health Service Contract Health Service delivery area. Am J Public Health 104(Suppl 3):S295-302. 2014. Available from: https://ajph.aphapublications.org/doi/ abs/10.2105/AJPH.2014.301933.

3. Espey DK, Jim MA, Cobb N, Bartholomew M, Becker T, Haverkamp $D$, Plescia M. Leading causes of death and all-cause mortality in American Indians and Alaska Natives. Am J Public Health 104(Suppl 3):S303-11. 2014.

4. Arias $E, X u J$, Jim MA. Period life tables for the non-Hispanic American Indian and Alaska Native population, 2007-2009. Am J Public Health 104(Suppl 3):S312-9. 2014. Available from: https:// ajph.aphapublications.org/doi/abs/10.2105/AJPH.2013.301635.

5. Rosenberg HM, Maurer JD, Sorlie PD, Johnson NJ, MacDorman MF, Hoyert DL, et al. Quality of death rates by race and Hispanic origin: A summary of current research, 1999. National Center for Health Statistics. Vital Health Stat 2(128). 1999. Available from: https://www.cdc.gov/nchs/data/series/sr_02/sr02_128.pdf.

6. Arias E, Schauman WS, Eschbach K, Sorlie PD, Backlund E. The validity of race and Hispanic origin reporting on death certificates in the United States. National Center for Health Statistics. Vital Health Stat 2(148). 2008. Available from: https://www.cdc.gov/ nchs/data/series/sr_02/sr02_148.pdf.

7. Sorlie PD, Rogot E, Johnson NJ. Validity of demographic characteristics on the death certificate. Epidemiology 3(2):181-4. 1992.

8. United States Census Office. Census reports, Volume IV: Twelfth census of the United States, taken in the year 1900. Vital statistics, part II statistics of deaths. Washington, D.C. 1902. Available from: https://www.cdc.gov/nchs/data/vsushistorical/ vsush_1900_4.pdf.

9. National Center for Health Statistics. Vital statistics of the United States, 1960, volume II-Mortality. Washington, DC. 1963.

10. Singh GK, Kochanek KD, MacDorman MF. Advance report of final mortality statistics, 1994. National Vital Statistics Reports; vol 45 no 3. Hyattsville, MD: National Center for Health Statistics. 1996. Available from: https://stacks.cdc.gov/view/cdc/52717.

11. Arias E, Xu J. United States life tables, 2018. National Vital Statistics Reports; vol 69 no 12. Hyattsville, MD: National Center for Health Statistics. 2020.

12. Hambright Z. Marital status, race, nativity, and country of origin on the death certificate and matching census record. National Center for Health Statistics. Vital Health Stat 2(34). 1969.
13. Espey DK, Jim MA, Richards TB, Begay C, Haverkamp D. Methods for improving the quality and completeness of mortality data for American Indians and Alaska Natives. Am J Public Health 104(Suppl 3):S286-94. 2014.

14. Murphy SL, Xu J, Kochanek KD, Arias E. Deaths: Final data for 2018. National Vital Statistics Reports; vol 69 no 13. Hyattsville, MD: National Center for Health Statistics. 2020. Available from: https://www.cdc.gov/nchs/data/nvsr/nvsr69/nvsr69-13-508.pdf.

15. Arias, E. R: Race crossover in longevity. In: Gu D, Dupre M (editors). Encyclopedia of gerontology and population aging. New York, NY: Springer Cham, 1-10. 2019.

16. National Center for Health Statistics. National Death Index user's guide. Hyattsville, MD. 2013. Available from: https://www.cdc.gov/nchs/data/ndi/ndi_users_guide.pdf.

17. Cowper DC, Kubal JD, Maynard C, Hynes DM. A primer and comparative review of major U.S. mortality databases. Ann Epidemiol 12(7):462-8. 2002.

18. Office of Management and Budget. Revisions to the standards for the classification of federal data on race and ethnicity. Fed Regist 62(210):58782-90. 1997. Available from:

https://www.resolutionmineeis.us/sites/default/files/references/ omb-standards-revisions-1997.pdf.

19. Anderson RN, Rosenberg H. Age standardization of death rates: Implementation of the year 2000 standard. National Vital Statistics Reports; vol 47 no 3. Hyattsville, MD: National Center for Health Statistics. 1998. Available from: https://www.cdc.gov/nchs/data/ nvsr/nvsr47/nvs47_03.pdf.

20. National Center for Health Statistics. User guide to the 2018 natality public use file. National Vital Statistics System. 2021. Available from: https://ftp.cdc.gov/pub/Health_Statistics/NCHS/ Dataset_Documentation/DVS/natality/UserGuide2018-508.pdf.

21. Ely DM, Driscoll AK. Infant mortality in the United States, 2019: Data from the Period Linked Birth/Infant Death File. 2021 [Forthcoming].

22. Shryock HS, Siegel JS, Larmon EA. The methods and materials of demography, vol 2. U.S. Bureau of the Census. Washington, DC: U.S. Government Printing Office. 1971.

23. Arias E, Curtin SC, Tejada-Vera B. Decennial life tables for 20092011, Methodology of the United States life tables. National Vital Statistics Reports; vol 69 no 10. Hyattsville, MD: National Center for Health Statistics. 2020.

24. Preston SM, Heuveline P, Guillot M. Demography: Measuring and modeling population processes. Oxford, England: Blackwell Publishers. 2001.

25. Brass W. On the scale of mortality. In: Brass W (editor). Biological aspects of demography. London, England: Taylor and Francis, 99-110. 1971.

26. Himes $\mathrm{CL}$, Preston $\mathrm{SH}$, Condran GA. A relational model of mortality at older ages in low mortality countries. Popul Stud 48(2):269-91. 1994. 


\section{List of Detailed Tables}

1. Number of deaths and death rates, adjusted for misclassification, and rate ratios by sex for the non-Hispanic American Indian or Alaska Native population: United States,

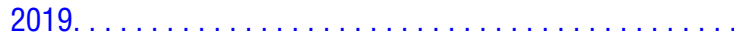

2. Number of deaths, percent of total deaths, age-adjusted death rates, and rate ratios by the 15 leading causes of death for the non-Hispanic American Indian or Alaska Native population, by sex: United States, 2019. . . . . . . . . . . .

3. Life table for the non-Hispanic American Indian or Alaska Native population: United States, 2019 ... . . . . . . . . . . .

4. Life table for non-Hispanic American Indian or Alaska Native males: United States, 2019 . . . . . . . . . . . . . . . . . .

5. Life table for non-Hispanic American Indian or Alaska Native females: United States, 2019 . . . . . . . . . . . . . . . . . . . 19

\section{List of Internet Tables}

(Available from: https://www.cdc.gov/nchs/data/nvsr/nvsr70/ nvsr70-12-tables.pdf.)

I-1. Deaths and death rates, by race and Hispanic origin, sex, and age: United States, 2019

$1-2$. Number of deaths and age-adjusted death rates for the 15 leading causes of death for the Non-Hispanic American Indian or Alaska Native population, by race and Hispanic origin and sex: United States, 2019 
Table 1. Number of deaths and death rates, adjusted for misclassification, and rate ratios by sex for the non-Hispanic American Indian or Alaska Native population: United States, 2019

[Race and Hispanic-origin categories are consistent with 1997 Office of Management and Budget standards]

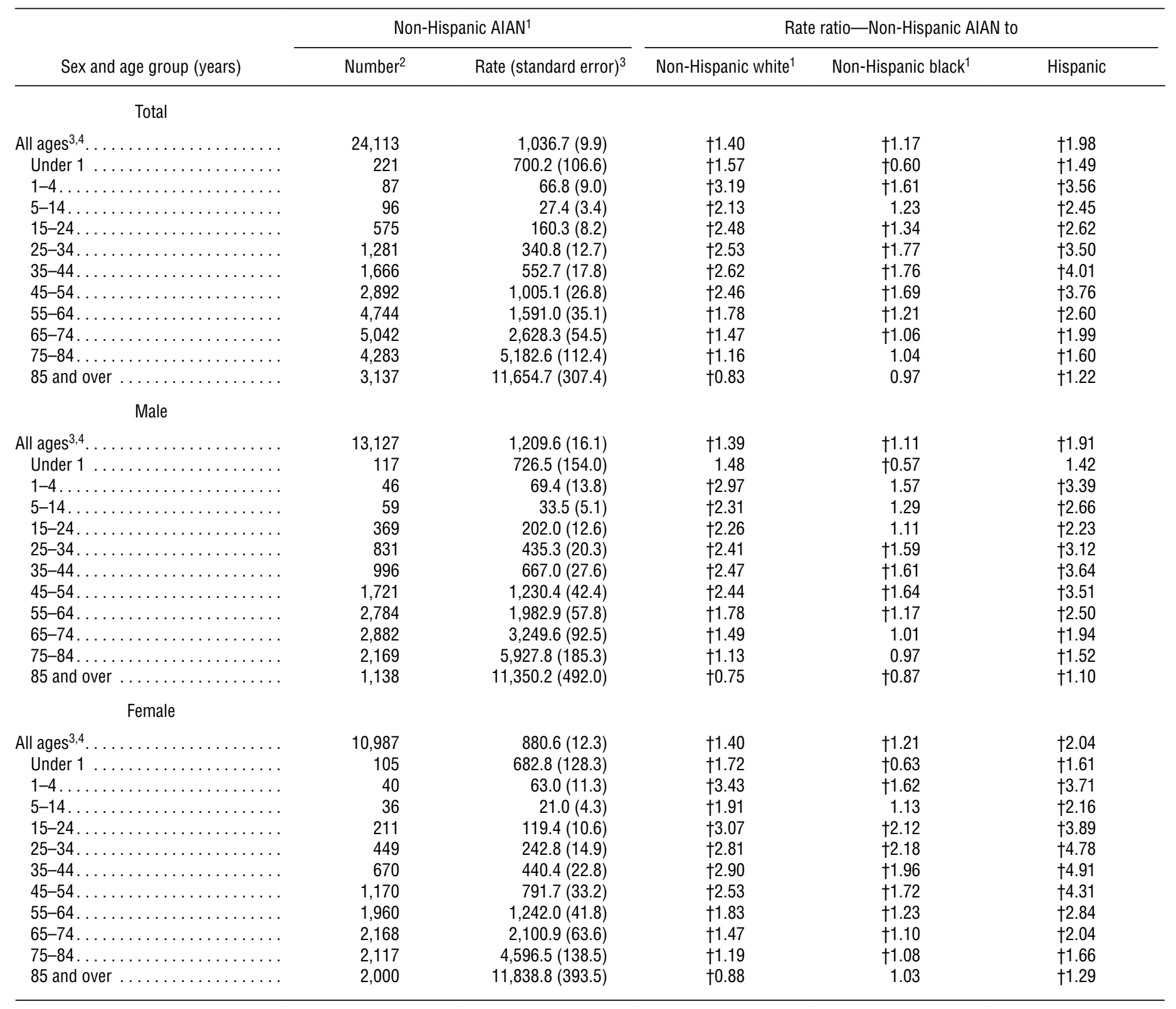

† Probability level less than 0.05 .

${ }^{1}$ Includes only one race reported on the death certificate.

${ }^{2}$ Numbers of deaths are adjusted using classification ratios for all ages and each age category separately. Numbers for each age group may not add to the total shown for all ages.

${ }^{3}$ Rate for non-Hispanic AIAN all ages is adjusted to a standard 2000 population; see Technical Notes in this report.

${ }^{4}$ Includes age not states.

NOTE: AIAN is American Indian or Alaska Native.

SOURCE: National Center for Health Statistics, National Vital Statistics System, Mortality. 
Table 2. Number of deaths, percent of total deaths, age-adjusted death rates, and rate ratios by the 15 leading causes of death for the non-Hispanic American Indian or Alaska Native population, by sex: United States, 2019

[Age-adjusted death rates are per 100,000 U.S standard population; see Technical Notes in this report. Asterisks $\left({ }^{\star}\right)$ preceding cause-of-death codes indicate they are not part of the International Classification of Diseases, 10th Revision (ICD-10); see Technical Notes. Race and Hispanic-origin categories are consistent with 1997 Office of Management and Budget standards]

\begin{tabular}{|c|c|c|c|c|c|c|c|}
\hline \multirow[b]{2}{*}{ Rank } & \multirow[b]{2}{*}{ Cause of death } & \multicolumn{3}{|c|}{ Non-Hispanic AIAN² } & \multicolumn{3}{|c|}{ Rate ratio-Non-Hispanic AIAN to } \\
\hline & & Number ${ }^{3}$ & $\begin{array}{l}\text { Percent } \\
\text { of total } \\
\text { deaths }\end{array}$ & $\begin{array}{c}\text { Rate } \\
\text { (standard error) }\end{array}$ & $\begin{array}{l}\text { Non-Hispanic } \\
\text { white }\end{array}$ & $\begin{array}{l}\text { Non-Hispanic } \\
\text { black }\end{array}$ & Hispanic \\
\hline \multicolumn{8}{|c|}{ Total } \\
\hline$\ldots$ & All causes...... . & 24,113 & 100.0 & $1,036.7(9.9)$ & $\dagger 1.40$ & $\dagger 1.17$ & $\dagger 1.98$ \\
\hline 1 & $\ldots \ldots \ldots \ldots|100-109| 11,,|113| 20-,\mid 51)$ & 4,619 & 19.2 & $198.9(4.5)$ & $\dagger 1.20$ & †0.97 & $\dagger 1.86$ \\
\hline 2 & Malignant neoplasms. . . . . . . . . . . . . . . . . . (C00-C97) & 4,188 & 17.4 & $172.2(3.9)$ & $\dagger 1.12$ & 0.99 & $\dagger 1.68$ \\
\hline 3 & Accidents (unintentional injuries). . . . . . . . . (V01-X59,Y85-Y86) & 2,554 & 10.6 & $106.4(2.9)$ & $\dagger 1.95$ & $\dagger 2.04$ & $\dagger 3.06$ \\
\hline 4 & Chronic liver disease and cirrhosis . & 1,251 & 5.2 & $49.7(1.8)$ & $\dagger 4.06$ & $\dagger 6.21$ & $\dagger 3.43$ \\
\hline 5 & Chronic lower respiratory diseases. & 1,192 & 4.9 & $50.2(2.4)$ & $\dagger 1.15$ & $\dagger 1.75$ & $\dagger 3.30$ \\
\hline 6 & 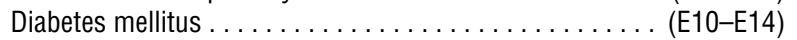 & 1,181 & 4.9 & $49.0(1.8)$ & †2.54 & $\dagger 1.29$ & $\dagger 1.98$ \\
\hline 7 & Cerebrovascular diseases $\ldots \ldots \ldots \ldots \ldots \ldots \ldots \ldots$ (I60-169) & 938 & 3.9 & $41.5(2.1)$ & $\dagger 1.19$ & †0.81 & $\dagger 1.33$ \\
\hline 8 & Intentional self-harm (suicide) . ......... ( $\left.{ }^{\star} \mathrm{U} 03, \mathrm{X} 60-\mathrm{X} 84, Y 87.0\right)$ & 701 & 2.9 & $29.3(1.6)$ & $\dagger 1.65$ & $\dagger 3.85$ & $\dagger 4.01$ \\
\hline \multirow[t]{2}{*}{9} & Nephritis, nephrotic syndrome and & & & & & & \\
\hline & nephrosis. . . . . . . . . . . . . . (N00-N07, N17-N19,N25-N27) & 484 & 2.0 & 20.7 (1.3) & $\dagger 1.84$ & $\dagger 0.84$ & $\dagger 1.83$ \\
\hline 10 & Influenza and pneumonia......................J09-J18) & 468 & 1.9 & $20.4(1.3)$ & $\dagger 1.65$ & $\dagger 1.49$ & $\dagger 2.14$ \\
\hline 11 & 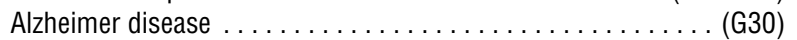 & 410 & 1.7 & $20.5(1.7)$ & †0.67 & †0.79 & †0.86 \\
\hline 12 & 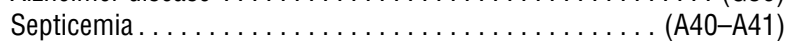 & 337 & 1.4 & $13.9(1.0)$ & $\dagger 1.49$ & $\dagger 0.88$ & $\dagger 2.13$ \\
\hline 13 & Assault (homicide) ............. $\left({ }^{\star} \mathrm{U} 01-{ }^{\star} \mathrm{U} 02, \mathrm{X} 85-\mathrm{Y} 09, \mathrm{Y} 87.1\right)$ & 327 & 1.4 & $13.5(0.9)$ & $\dagger 5.00$ & †0.55 & $\nmid 2.67$ \\
\hline \multirow[t]{2}{*}{14} & Essential hypertension and & & & & & & \\
\hline & hypertensive renal disease $\ldots \ldots \ldots \ldots \ldots \ldots \ldots(|10| 112,, \mid 15)$ & 229 & 0.9 & $10.2(1.0)$ & $\dagger 1.29$ & †0.61 & 1.29 \\
\hline 15 & Pneumonitis due to solids and liquids . . . . . . . . . . . . .(J69) & 172 & 0.7 & $7.6(1.0)$ & $\dagger 1.57$ & $\dagger 1.51$ & $\dagger 2.51$ \\
\hline \multirow[t]{2}{*}{$\ldots$} & All other causes . ....................... (residual) & 4,977 & 20.6 & $211.7(4.3)$ & $\dagger 1.36$ & $\dagger 1.18$ & $† 2.09$ \\
\hline & Male & & & & & & \\
\hline$\ldots$ & All causes. ............ & 13,127 & 100.0 & $1,209.6(16.1)$ & $\dagger 1.39$ & $\dagger 1.11$ & $\dagger 1.91$ \\
\hline 1 & Diseases of heart . . . . . . . . . . . . . (100-109,I11,I13,I20-I51) & 2,759 & 21.0 & $257.7(7.9)$ & $\dagger 1.23$ & 0.99 & $\dagger 1.90$ \\
\hline 2 & Malignant neoplasms. . . . . . . . . . . . . . . . (C00-C97) & 2,219 & 16.9 & $200.0(6.4)$ & $\dagger 1.11$ & 0.95 & $\dagger 1.66$ \\
\hline 3 & Accidents (unintentional injuries). . . . . . . . . (V01-X59,Y85-Y86) & 1,601 & 12.2 & $138.7(4.8)$ & $\dagger 1.88$ & $\dagger 1.76$ & †2.67 \\
\hline 4 & Diabetes mellitus . . . . . . . . . . . . . . . . . . . (E10-E14) & 631 & 4.8 & $56.6(3.0)$ & $\dagger 2.26$ & $\dagger 1.23$ & $\dagger 1.88$ \\
\hline 5 & Chronic liver disease and cirrhosis . . . . . . . . . . . K70,K73-K74) & 629 & 4.8 & $51.7(2.6)$ & $\dagger 3.25$ & $\dagger 4.68$ & $\dagger 2.50$ \\
\hline 6 & Chronic lower respiratory diseases . . . . . . . . . . . . . (J40-J47) & 587 & 4.5 & $54.9(3.9)$ & $\dagger 1.20$ & $\dagger 1.53$ & †2.97 \\
\hline 7 & Intentional self-harm (suicide) . . . . . . . . . ( $\left.{ }^{\star} U 03, X 60-X 84, Y 87.0\right)$ & 531 & 4.0 & $45.6(3.1)$ & $\dagger 1.62$ & †3.60 & †3.92 \\
\hline 8 & Cerebrovascular diseases . . . . . . . . . . . . . . . . . (160-169) & 428 & 3.3 & $42.4(3.4)$ & $\dagger 1.22$ & †0.76 & $\dagger 1.27$ \\
\hline 9 & Assault (homicide)............... $\left({ }^{\star} U 01-{ }^{\star} U 02, X 85-Y 09, Y 87.1\right)$ & 237 & 1.8 & $19.6(1.6)$ & $\dagger 5.37$ & $\dagger 0.45$ & $\dagger 2.46$ \\
\hline \multirow[t]{2}{*}{10} & Nephritis, nephrotic syndrome and & & & & & & \\
\hline & nephrosis................... .N00-N07, N17-N19,N25-N27) & 235 & 1.8 & $22.3(2.1)$ & $\dagger 1.63$ & t0.75 & $\dagger 1.67$ \\
\hline 11 & Influenza and pneumonia. .....................J09-J18) & 204 & 1.6 & $19.8(1.9)$ & $\dagger 1.40$ & 1.21 & $\dagger 1.73$ \\
\hline 12 & Septicemia . . . . . . . . . . . . . . . . . . . & 177 & 1.4 & $15.5(1.7)$ & $\dagger 1.50$ & 0.85 & $† 2.03$ \\
\hline 13 & Alzheimer disease $\ldots \ldots \ldots \ldots \ldots \ldots \ldots \ldots \ldots \ldots \ldots \ldots \ldots \ldots \ldots \ldots$ & 120 & 0.9 & $14.1(2.3)$ & †0.59 & †0.68 & †0.74 \\
\hline 14 & Pneumonitis due to solids and liquids . . . . . . . . . . . . (J69) & 118 & 0.9 & $13.5(3.1)$ & $\nmid 2.06$ & $\dagger 1.96$ & $\dagger 3.26$ \\
\hline \multirow[t]{2}{*}{15} & Essential hypertension and & & & & & & \\
\hline & hypertensive renal disease. ...... & 113 & 0.9 & $11.0(1.7)$ & $\dagger 1.31$ & $\dagger 0.58$ & $\dagger 1.26$ \\
\hline$\ldots$ & All other causes $\ldots \ldots \ldots \ldots \ldots \ldots \ldots \ldots \ldots$ (residual $)$ & 2,498 & 19.0 & $226.4(6.7)$ & $\dagger 1.35$ & $\dagger 1.11$ & $† 2.01$ \\
\hline
\end{tabular}


Table 2. Number of deaths, percent of total deaths, age-adjusted death rates, and rate ratios by the 15 leading causes of death for the non-Hispanic American Indian or Alaska Native population, by sex: United States, 2019-Con.

[Age-adjusted death rates are per 100,000 U.S standard population; see Technical Notes in this report. Asterisks $\left(^{\star}\right)$ preceding cause-of-death codes indicate they are not part of the International Classification of Diseases, 10th Revision (ICD-10); see Technical Notes. Race and Hispanic-origin categories are consistent with 1997 Office of Management and Budget standards]

\begin{tabular}{|c|c|c|c|c|c|c|c|}
\hline \multirow[b]{2}{*}{ Rank $^{1}$} & \multirow[b]{2}{*}{ Cause of death } & \multicolumn{3}{|c|}{ Non-Hispanic AIAN² } & \multicolumn{3}{|c|}{ Rate ratio-Non-Hispanic AIAN to } \\
\hline & & Number ${ }^{3}$ & $\begin{array}{l}\text { Percent } \\
\text { of total } \\
\text { deaths }\end{array}$ & $\begin{array}{c}\text { Rate } \\
\text { (standard error) }\end{array}$ & $\begin{array}{c}\text { Non-Hispanic } \\
\text { white }\end{array}$ & $\begin{array}{c}\text { Non-Hispanic } \\
\text { black }\end{array}$ & Hispanic \\
\hline \multicolumn{8}{|c|}{ Female } \\
\hline$\ldots$ & All causes. . . . . . . & 10,987 & 100.0 & $880.6(12.3)$ & $\dagger 1.40$ & $\dagger 1.21$ & $† 2.04$ \\
\hline 1 & Malignant neoplasms.... & 1,965 & 17.9 & $149.5(4.9)$ & $\dagger 1.12$ & 1.00 & $\dagger 1.67$ \\
\hline 2 & Diseases of heart . . . . . . . . . . . . . . $(100-109,|111| 13,, \mid 20-151)$ & 1,862 & 16.9 & $148.1(5.1)$ & $\dagger 1.15$ & †0.92 & $\dagger 1.78$ \\
\hline 3 & Accidents (unintentional injuries) ...........(V01-X59,Y85-Y86) & 957 & 8.7 & $77.4(3.6)$ & $\dagger 2.15$ & $\dagger 2.66$ & $\dagger 4.35$ \\
\hline 4 & Chronic liver disease and cirrhosis . . . . . . . . . . . . K70,K73-K74) & 625 & 5.7 & $48.2(2.5)$ & $\dagger 5.48$ & $\dagger 8.60$ & $\dagger 5.51$ \\
\hline 5 & Chronic lower respiratory diseases . . . . . . . . . . . . . . (J40-J47) & 606 & 5.5 & $46.5(3.0)$ & 1.11 & $\dagger 1.93$ & $\dagger 3.61$ \\
\hline 6 & Diabetes mellitus $\ldots \ldots \ldots \ldots \ldots \ldots \ldots \ldots \ldots \ldots$ (E10-E14) & 551 & 5.0 & $42.5(2.2)$ & $\uparrow 2.95$ & $\dagger 1.32$ & $\dagger 2.08$ \\
\hline 7 & Cerebrovascular diseases . . . . . . . . . . . . . . . . . . . . . (I60-169) & 510 & 4.6 & $40.6(2.6)$ & $\dagger 1.17$ & $\dagger 0.86$ & $\dagger 1.39$ \\
\hline 8 & Alzheimer disease $\ldots \ldots \ldots \ldots \ldots \ldots \ldots \ldots \ldots \ldots \ldots \ldots \ldots \ldots \ldots$ & 290 & 2.6 & $24.6(2.3)$ & $\dagger 0.71$ & †0.87 & 10.9 \\
\hline 9 & Influenza and pneumonia . .....................J09-J18) & 265 & 2.4 & $21.1(1.9)$ & $\dagger 1.92$ & $\dagger 1.81$ & $† 2.64$ \\
\hline \multirow[t]{2}{*}{10} & Nephritis, nephrotic syndrome and & & & & & & \\
\hline & nephrosis. . . . . . . . . . . . . . (N00-N07, N17-N19,N25-N27) & 248 & 2.3 & $19.2(1.7)$ & $\dagger 2.04$ & 10.9 & $\dagger 1.99$ \\
\hline 11 & Intentional self-harm (suicide) . . . . . . . . . ( ${ }^{*}$ U03,X60-X84,Y87.0) & 167 & 1.5 & $14.1(1.6)$ & $\dagger 1.86$ & $\dagger 4.82$ & $\dagger 4.77$ \\
\hline 12 & Septicemia. . . . . . . . . . . . . . . . . . . . . (A40-A41) & 162 & 1.5 & $12.5(1.3)$ & $\dagger 1.46$ & 0.87 & $\dagger 2.21$ \\
\hline \multirow[t]{2}{*}{13} & Essential hypertension and & & & & & & \\
\hline & hypertensive renal disease $\ldots \ldots \ldots \ldots \ldots \ldots \ldots(|110| 112,, \mid 15)$ & 116 & 1.1 & $9.9(1.4)$ & 1.34 & †0.65 & 1.35 \\
\hline 14 & 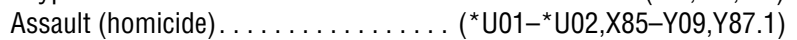 & 90 & 0.8 & $7.3(1.1)$ & $\dagger 4.21$ & 1.14 & $\dagger 3.68$ \\
\hline 15 & Pneumonitis due to solids and liquids . . . . . . . . . . . . . (J69) & 63 & 0.6 & $4.8(0.8)$ & 1.31 & 1.23 & $\dagger 2.12$ \\
\hline$\ldots$ & All other causes $\ldots \ldots \ldots \ldots \ldots \ldots \ldots \ldots \ldots \ldots$ (residual) & 2,479 & 22.6 & $196.1(5.6)$ & $\dagger 1.37$ & $\dagger 1.23$ & $\dagger 2.16$ \\
\hline
\end{tabular}

Category not applicable.

† Probability level less than 0.05 .

${ }^{1}$ Rank based on adjusted number of deaths to misclassification of non-Hispanic AIAN on death certificates; see Technical Notes.

${ }^{2}$ Includes only one race reported on the death certificate.

${ }^{3}$ Numbers of deaths are adjusted using classification ratios for all causes and each cause separately. Numbers for each cause may not add to the total shown for all causes.

SOURCE: National Center for Health Statistics, National Vital Statistics System, Mortality. 
Table 3. Life table for the non-Hispanic American Indian or Alaska Native population: United States, 2019

\begin{tabular}{|c|c|c|c|c|c|c|}
\hline & $\begin{array}{c}\text { Probability of dying } \\
\text { between ages } \\
x \text { and } x+1\end{array}$ & $\begin{array}{c}\text { Number surviving } \\
\text { to age } x\end{array}$ & $\begin{array}{c}\text { Number dying } \\
\text { between ages } x \text { and } \\
x+1\end{array}$ & $\begin{array}{c}\text { Person-years lived } \\
\text { between ages } \\
x \text { and } x+1\end{array}$ & $\begin{array}{l}\text { Total number of } \\
\text { person-years lived } \\
\text { above age } x\end{array}$ & $\begin{array}{c}\text { Expectation of life } \\
\text { at age } x\end{array}$ \\
\hline Age (years) & $q_{x}$ & $I_{x}$ & $d_{x}$ & $L_{x}$ & $T_{x}$ & $e_{x}$ \\
\hline$\ldots \ldots \ldots$ & 0.007871 & 100,000 & 787 & 99,385 & $7,175,096$ & 71.8 \\
\hline $1-2 \ldots$ & 0.000989 & 99,213 & 98 & 99,164 & $7,075,711$ & 71.3 \\
\hline $2-3 \ldots$ & 0.000657 & 99,115 & 65 & 99,082 & $6,976,547$ & 70.4 \\
\hline $3-4 \ldots$ & 0.000476 & 99,050 & 47 & 99,026 & $6,877,465$ & 69.4 \\
\hline $4-5 \ldots$ & 0.000469 & 99,003 & 46 & 98,979 & $6,778,439$ & 68.5 \\
\hline $5-6 \ldots$ & 0.000309 & 98,956 & 31 & 98,941 & $6,679,460$ & 67.5 \\
\hline $6-7 \ldots$ & 0.000257 & 98,925 & 25 & 98,913 & $6,580,519$ & 66.5 \\
\hline $7-8 \ldots$ & 0.000221 & 98,900 & 22 & 98,889 & $6,481,606$ & 65.5 \\
\hline $8-9$. & 0.000190 & 98,878 & 19 & 98,869 & $6,382,717$ & 64.6 \\
\hline $9-10 \ldots$ & 0.000166 & 98,859 & 16 & 98,851 & $6,283,848$ & 63.6 \\
\hline $10-11 \ldots \ldots \ldots \ldots$ & 0.000158 & 98,843 & 16 & 98.835 & 6.184 .997 & 62.6 \\
\hline $11-12 \ldots \ldots \ldots \ldots$ & 0.000184 & 98,827 & 18 & 98,818 & $6,086,162$ & 61.6 \\
\hline $12-13 \ldots \ldots \ldots \ldots$ & 0.000268 & 98,809 & 26 & 98,796 & $5,987,343$ & 60.6 \\
\hline $13-14$. & 0.000419 & 98,783 & 41 & 98,762 & $5,888,547$ & 59.6 \\
\hline $14-15 \ldots$ & 0.000622 & 98,741 & 61 & 98,711 & $5,789,785$ & 58.6 \\
\hline $15-16 \ldots \ldots \ldots \ldots$ & 0.000858 & 98,680 & 85 & 98,638 & $5,691,075$ & 57.7 \\
\hline $16-17 \ldots \ldots \ldots \ldots$ & 0.001090 & 98,595 & 107 & 98,542 & $5,592,437$ & 56.7 \\
\hline $17-18 \ldots \ldots \ldots \ldots$ & 0.001291 & 98,488 & 127 & 98,424 & $5,493,895$ & 55.8 \\
\hline $18-19 .$. & 0.001440 & 98,361 & 142 & 98,290 & $5,395,471$ & 54.9 \\
\hline 19-20. . & 0.001552 & 98,219 & 152 & 98,143 & $5,297,181$ & 53.9 \\
\hline$\ldots \ldots \ldots$ & 0.001664 & 98,066 & 163 & 97,985 & $5,199,039$ & 53.0 \\
\hline $21-22 \ldots \ldots \ldots \ldots$ & 0.001796 & 97,903 & 176 & 97,815 & $5,101,054$ & 52.1 \\
\hline $22-23$. & 0.001936 & 97,728 & 189 & 97,633 & $5,003,238$ & 51.2 \\
\hline 23-24. . & 0.002083 & 97,538 & 203 & 97,437 & $4,905,605$ & 50.3 \\
\hline $24-25$. & 0.002233 & 97,335 & 217 & 97,226 & $4,808,169$ & 49.4 \\
\hline $25-26$. & 0.002365 & 97,118 & 230 & 97,003 & $4,710,942$ & 48.5 \\
\hline $26-27$. & 0.002497 & 96,888 & 242 & 96,767 & $4,613,939$ & 47.6 \\
\hline $27-28$. & 0.002671 & 96,646 & 258 & 96,517 & $4,517,172$ & 46.7 \\
\hline $28-29$. & 0.002916 & 96,388 & 281 & 96,248 & $4,420,655$ & 45.9 \\
\hline $29-30 \ldots \ldots \ldots \ldots$ & 0.003225 & 96,107 & 310 & 95,952 & $4,324,407$ & 45.0 \\
\hline $30-31 \ldots \ldots \ldots \ldots$ & 0.003587 & 95,797 & 344 & 95,625 & $4,228,455$ & 44.1 \\
\hline $31-32 \ldots \ldots \ldots \ldots$ & 0.003950 & 95,453 & 377 & 95,265 & $4,132,830$ & 43.3 \\
\hline $32-33 \ldots \ldots \ldots \ldots$ & 0.004268 & 95,076 & 406 & 94,873 & $4,037,565$ & 42.5 \\
\hline $33-34 \ldots \ldots \ldots \ldots$ & 0.004490 & 94,671 & 425 & 94,458 & $3,942,692$ & 41.6 \\
\hline $34-35 \ldots \ldots \ldots \ldots$ & 0.004630 & 94,245 & 436 & 94,027 & $3,848,233$ & 40.8 \\
\hline $35-36 \ldots \ldots \ldots \ldots$ & 0.004767 & 93,809 & 447 & 93,585 & $3,754,206$ & 40.0 \\
\hline $36-37 \ldots \ldots \ldots \ldots$ & 0.004933 & 93,362 & 461 & 93,132 & $3,660,621$ & 39.2 \\
\hline $37-38 \ldots \ldots \ldots \ldots$ & 0.005078 & 92,901 & 472 & 92,665 & $3,567,489$ & 38.4 \\
\hline$\ldots \ldots \ldots$ & 0.005206 & 92,430 & 481 & 92,189 & $3,474,824$ & 37.6 \\
\hline $39-40 \ldots \ldots \ldots \ldots$ & 0.005336 & 91,948 & 491 & 91,703 & $3,382,635$ & 36.8 \\
\hline $40-41 \ldots \ldots \ldots \ldots$ & 0.005463 & 91,458 & 500 & 91,208 & $3,290,932$ & 36.0 \\
\hline $41-42 \ldots \ldots \ldots \ldots$ & 0.005631 & 90,958 & 512 & 90,702 & $3,199,724$ & 35.2 \\
\hline $42-43 \ldots \ldots \ldots \ldots$ & 0.005904 & 90,446 & 534 & 90,179 & $3,109,022$ & 34.4 \\
\hline $43-44 \ldots \ldots \ldots \ldots$ & 0.006312 & 89,912 & 568 & 89,628 & $3,018,843$ & 33.6 \\
\hline $44-45 \ldots \ldots \ldots \ldots$ & 0.006819 & 89,344 & 609 & 89,040 & $2,929,215$ & 32.8 \\
\hline $45-46 \ldots \ldots \ldots \ldots$ & 0.007356 & 88,735 & 653 & 88,409 & $2,840,175$ & 32.0 \\
\hline $46-47 \ldots \ldots \ldots \ldots$ & 0.007894 & 88,082 & 695 & 87,735 & $2,751,766$ & 31.2 \\
\hline $47-48 \ldots \ldots \ldots \ldots$ & 0.008456 & 87,387 & 739 & 87,018 & $2,664,031$ & 30.5 \\
\hline $48-49 . \ldots \ldots \ldots \ldots$ & 0.009044 & 86,648 & 784 & 86,256 & $2,577,013$ & 29.7 \\
\hline $49-50 \ldots \ldots \ldots \ldots \ldots$ & 0.009655 & 85,865 & 829 & 85,450 & $2,490,757$ & 29.0 \\
\hline $50-51 \ldots \ldots \ldots \ldots$ & 0.010299 & 85,036 & 876 & 84,598 & $2,405,307$ & 28.3 \\
\hline $51-52 \ldots \ldots \ldots \ldots$ & 0.010947 & 84,160 & 921 & 83,699 & $2,320,709$ & 27.6 \\
\hline $52-53 \ldots \ldots \ldots \ldots$ & 0.011548 & 83,238 & 961 & 82,758 & $2,237,010$ & 26.9 \\
\hline $53-54 \ldots$ & 0.012062 & 82,277 & 992 & 81,781 & $2,154,252$ & 26.2 \\
\hline $54-55 \ldots \ldots \ldots \ldots$ & 0.012506 & 81,285 & 1,017 & 80,777 & $2,072,471$ & 25.5 \\
\hline $55-56 \ldots \ldots \ldots \ldots$ & 0.012899 & 80,268 & 1,035 & 79,751 & $1,991,695$ & 24.8 \\
\hline $56-57 \ldots \ldots \ldots \ldots$ & 0.013313 & 79,233 & 1,055 & 78,705 & $1,911,944$ & 24.1 \\
\hline $57-58 \ldots \ldots \ldots \ldots$ & 0.013815 & 78,178 & 1,080 & 77,638 & $1,833,239$ & 23.4 \\
\hline $58-59 \ldots \ldots \ldots \ldots \ldots$ & 0.014466 & 77,098 & 1,115 & 76,540 & $1,755,601$ & 22.8 \\
\hline $59-60 \ldots \ldots \ldots \ldots \ldots$ & 0.015253 & 75,983 & 1,159 & 75,403 & $1,679,060$ & 22.1 \\
\hline
\end{tabular}


Table 3. Life table for the non-Hispanic American Indian or Alaska Native population: United States, 2019—Con.

\begin{tabular}{|c|c|c|c|c|c|c|}
\hline & $\begin{array}{c}\text { Probability of dying } \\
\text { between ages } \\
x \text { and } x+1\end{array}$ & $\begin{array}{c}\text { Number surviving } \\
\text { to age } x\end{array}$ & $\begin{array}{c}\text { Number dying } \\
\text { between ages } x \text { and } \\
x+1\end{array}$ & $\begin{array}{c}\text { Person-years lived } \\
\text { between ages } \\
x \text { and } x+1\end{array}$ & $\begin{array}{l}\text { Total number of } \\
\text { person-years lived } \\
\text { above age } x\end{array}$ & $\begin{array}{c}\text { Expectation of life } \\
\text { at age } x\end{array}$ \\
\hline Age (years) & $q_{x}$ & $I_{x}$ & $d_{x}$ & $L_{x}$ & $T_{x}$ & $e_{x}$ \\
\hline$\ldots \ldots \ldots \ldots$ & 0.016116 & 74,824 & 1,206 & 74,221 & $1,603,657$ & 21.4 \\
\hline $61-62 .$. & 0.016989 & 73,618 & 1,251 & 72,993 & $1,529,436$ & 20.8 \\
\hline 62-63.. & 0.017881 & 72,367 & 1,294 & 71,720 & $1,456,443$ & 20.1 \\
\hline $63-64 \ldots \ldots \ldots \ldots$ & 0.018772 & 71,073 & 1,334 & 70,406 & $1,384,723$ & 19.5 \\
\hline $64-65 \ldots \ldots \ldots \ldots$ & 0.019685 & 69,739 & 1,373 & 69,053 & $1,314,317$ & 18.8 \\
\hline $65-66 .$. & 0.020684 & 68,366 & 1,414 & 67,659 & $1,245,264$ & 18.2 \\
\hline $66-67$. & 0.021800 & 66,952 & 1,460 & 66,222 & $1,177,605$ & 17.6 \\
\hline 67-68. . & 0.022992 & 65,493 & 1,506 & 64,740 & $1,111,383$ & 17.0 \\
\hline$\ldots \ldots \ldots$ & 0.024240 & 63,987 & 1,551 & 63,211 & $1,046,643$ & 16.4 \\
\hline $69-70 \ldots \ldots \ldots \ldots$ & 0.025543 & 62,436 & 1,595 & 61,638 & 983,432 & 15.8 \\
\hline 70-71. . & 0.026959 & 60,841 & 1,640 & 60,021 & 921,793 & 15.2 \\
\hline $71-72$. & 0.028511 & 59,201 & 1,688 & 58,357 & 861,773 & 14.6 \\
\hline $72-73 \ldots \ldots \ldots \ldots$ & 0.030165 & 57,513 & 1,735 & 56,645 & 803,416 & 14.0 \\
\hline $73-74 \ldots \ldots \ldots \ldots$ & 0.031949 & 55,778 & 1,782 & 54,887 & 746,770 & 13.4 \\
\hline $74-75 \ldots \ldots \ldots \ldots$ & 0.033938 & 53,996 & 1,833 & 53,080 & 691,883 & 12.8 \\
\hline $75-76 \ldots \ldots \ldots \ldots$ & 0.036136 & 52,163 & 1,885 & 51,221 & 638,804 & 12.2 \\
\hline $76-77 .$. & 0.038684 & 50,278 & 1,945 & 49,306 & 587,583 & 11.7 \\
\hline$\ldots \ldots \ldots \ldots$ & 0.041817 & 48,334 & 2,021 & 47,323 & 538,277 & 11.1 \\
\hline $78-79 \ldots \ldots \ldots \ldots$ & 0.045653 & 46,312 & 2,114 & 45,255 & 490,954 & 10.6 \\
\hline $79-80 \ldots \ldots \ldots \ldots$ & 0.050091 & 44,198 & 2,214 & 43,091 & 445,698 & 10.1 \\
\hline $80-81 \ldots \ldots \ldots \ldots$ & 0.055028 & 41,984 & 2,310 & 40,829 & 402,607 & 9.6 \\
\hline $81-82 \ldots$ & 0.059921 & 39,674 & 2,377 & 38,485 & 361,778 & 9.1 \\
\hline $82-83 \ldots \ldots \ldots \ldots$ & 0.064717 & 37,297 & 2,414 & 36,090 & 323,293 & 8.7 \\
\hline $83-84 \ldots \ldots \ldots \ldots$ & 0.069436 & 34,883 & 2,422 & 33,672 & 287,203 & 8.2 \\
\hline $84-85 \ldots \ldots \ldots \ldots$ & 0.074300 & 32,461 & 2,412 & 31,255 & 253,532 & 7.8 \\
\hline $85-86 \ldots$ & 0.080514 & 30,049 & 2,419 & 28,839 & 222,277 & 7.4 \\
\hline $86-87 \ldots \ldots \ldots \ldots$ & 0.086669 & 27,630 & 2,395 & 26,432 & 193,438 & 7.0 \\
\hline $87-88 \ldots \ldots \ldots \ldots$ & 0.094191 & 25,235 & 2,377 & 24,046 & 167,005 & 6.6 \\
\hline $88-89 . \ldots \ldots \ldots \ldots$ & 0.102228 & 22,858 & 2,337 & 21,690 & 142,959 & 6.3 \\
\hline $89-90 \ldots \ldots \ldots \ldots$ & 0.110790 & 20,521 & 2,274 & 19,385 & 121,269 & 5.9 \\
\hline $90-91 \ldots \ldots \ldots \ldots$. & 0.119880 & 18,248 & 2,188 & 17,154 & 101,885 & 5.6 \\
\hline $91-92 \ldots \ldots \ldots \ldots$ & 0.129495 & 16,060 & 2,080 & 15,020 & 84,731 & 5.3 \\
\hline $92-93 \ldots \ldots \ldots \ldots$ & 0.139627 & 13,980 & 1,952 & 13,004 & 69,710 & 5.0 \\
\hline $93-94 \ldots \ldots \ldots \ldots$ & 0.150258 & 12,028 & 1,807 & 11,125 & 56,706 & 4.7 \\
\hline $94-95 \ldots \ldots \ldots \ldots$ & 0.161361 & 10,221 & 1,649 & 9,396 & 45,581 & 4.5 \\
\hline $95-96 \ldots \ldots \ldots \ldots$ & 0.172901 & 8,572 & 1,482 & 7,831 & 36,185 & 4.2 \\
\hline $96-97 \ldots \ldots \ldots \ldots$ & 0.184835 & 7,090 & 1,310 & 6,434 & 28,354 & 4.0 \\
\hline $97-98 \ldots \ldots \ldots \ldots$ & 0.197108 & 5,779 & 1,139 & 5,210 & 21,920 & 3.8 \\
\hline $98-99 . \ldots \ldots \ldots \ldots$ & 0.209657 & 4,640 & 973 & 4,154 & 16,710 & 3.6 \\
\hline $99-100 \ldots \ldots \ldots \ldots$ & 0.222411 & 3,667 & 816 & 3,259 & 12,556 & 3.4 \\
\hline 100 and over .......... & 1.000000 & 2,852 & 2,852 & 9,297 & 9,297 & 3.3 \\
\hline
\end{tabular}

NOTE: This life table is based on death rates that have been adjusted for race and Hispanic-origin misclassification on death certificates.

SOURCE: National Center for Health Statistics, National Vital Statistics System, Mortality. 
Table 4. Life table for non-Hispanic American Indian or Alaska Native males: United States, 2019

\begin{tabular}{|c|c|c|c|c|c|c|}
\hline & $\begin{array}{c}\text { Probability of dying } \\
\text { between ages } \\
x \text { and } x+1\end{array}$ & $\begin{array}{c}\text { Number surviving } \\
\text { to age } x\end{array}$ & $\begin{array}{c}\text { Number dying } \\
\text { between ages } x \text { and } \\
x+1\end{array}$ & $\begin{array}{c}\text { Person-years lived } \\
\text { between ages } \\
x \text { and } x+1\end{array}$ & $\begin{array}{l}\text { Total number of } \\
\text { person-years lived } \\
\text { above age } x\end{array}$ & $\begin{array}{c}\text { Expectation of life } \\
\text { at age } x\end{array}$ \\
\hline Age (years) & $q_{x}$ & $I_{x}$ & $d_{x}$ & $L_{x}$ & $T_{x}$ & $e_{x}$ \\
\hline$\ldots \ldots \ldots$ & 0.008649 & 100,000 & 865 & 99,331 & $6,864,446$ & 68.6 \\
\hline $1-2$. & 0.001063 & 99,135 & 105 & 99,082 & $6,765,116$ & 68.2 \\
\hline $2-3$. & 0.000626 & 99,030 & 62 & 98,999 & $6,666,033$ & 67.3 \\
\hline$\ldots \ldots \ldots \ldots$ & 0.000274 & 98,968 & 27 & 98,954 & $6,567,034$ & 66.4 \\
\hline$\ldots \ldots \ldots \ldots$ & 0.000540 & 98,941 & 53 & 98,914 & $6,468,080$ & 65.4 \\
\hline$\ldots \ldots \ldots \ldots$ & 0.000265 & 98,887 & 26 & 98,874 & $6,369,166$ & 64.4 \\
\hline $6-7 \ldots$ & 0.000224 & 98,861 & 22 & 98,850 & $6,270,292$ & 63.4 \\
\hline$\ldots \ldots \ldots$ & 0.000206 & 98,839 & 20 & 98,829 & $6,171,442$ & 62.4 \\
\hline $8-9 \ldots \ldots \ldots \ldots \ldots$ & 0.000204 & 98,818 & 20 & 98,808 & $6,072,614$ & 61.5 \\
\hline $9-10 \ldots \ldots \ldots \ldots \ldots$ & 0.000217 & 98,798 & 21 & 98,788 & $5,973,805$ & 60.5 \\
\hline$\ldots \ldots \ldots$ & 0.000252 & 98,777 & 25 & 98,764 & $5,875,018$ & 59.5 \\
\hline$\ldots \ldots \ldots \ldots$ & 0.000320 & 98,752 & 32 & 98,736 & $5,776,253$ & 58.5 \\
\hline $12-13 . \ldots \ldots \ldots \ldots$ & 0.000438 & 98,720 & 43 & 98,699 & $5,677,517$ & 57.5 \\
\hline $13-14 \ldots \ldots \ldots \ldots$ & 0.000611 & 98,677 & 60 & 98,647 & $5,578,818$ & 56.5 \\
\hline$\ldots \ldots \ldots$ & 0.000828 & 98,617 & 82 & 98,576 & $5,480,171$ & 55.6 \\
\hline$\ldots \ldots \ldots$ & 0.001076 & 98,535 & 106 & 98,482 & $5,381,595$ & 54.6 \\
\hline$\ldots \ldots \ldots$ & 0.001327 & 98,429 & 131 & 98,364 & $5,283,113$ & 53.7 \\
\hline$\ldots \ldots \ldots$ & 0.001557 & 98,299 & 153 & 98,222 & $5,184,749$ & 52.7 \\
\hline$\ldots \ldots \ldots$ & 0.001748 & 98,146 & 172 & 98,060 & $5,086,527$ & 51.8 \\
\hline$\ldots \ldots \ldots$ & 0.001915 & 97,974 & 188 & 97,880 & $4,988,468$ & 50.9 \\
\hline$\ldots \ldots \ldots \ldots$ & 0.002081 & 97,786 & 203 & 97,685 & $4,890,587$ & 50.0 \\
\hline $21-22 . \ldots \ldots \ldots \ldots$ & 0.002269 & 97,583 & 221 & 97,472 & $4,792,903$ & 49.1 \\
\hline $22-23 . \ldots \ldots \ldots \ldots$ & 0.002477 & 97,362 & 241 & 97,241 & $4,695,431$ & 48.2 \\
\hline $23-24 \ldots \ldots \ldots \ldots$ & 0.002705 & 97,120 & 263 & 96,989 & $4,598,190$ & 47.3 \\
\hline $24-25 \ldots$ & 0.002935 & 96,858 & 284 & 96,716 & $4,501,201$ & 46.5 \\
\hline 25-26. & 0.003144 & 96,573 & 304 & 96,422 & $4,404,485$ & 45.6 \\
\hline$\ldots \ldots \ldots$ & 0.003342 & 96,270 & 322 & 96,109 & $4,308,063$ & 44.7 \\
\hline $27-28 \ldots \ldots \ldots \ldots \ldots$ & 0.003567 & 95,948 & 342 & 95,777 & $4,211,955$ & 43.9 \\
\hline$\ldots \ldots \ldots \ldots$ & 0.003845 & 95,606 & 368 & 95,422 & $4,116,178$ & 43.1 \\
\hline $29-30$. & 0.004179 & 95,238 & 398 & 95,039 & $4,020,756$ & 42.2 \\
\hline 30-31. & 0.004564 & 94,840 & 433 & 94,624 & $3,925,716$ & 41.4 \\
\hline$\ldots \ldots \ldots \ldots$ & 0.004953 & 94,407 & 468 & 94,174 & $3,831,092$ & 40.6 \\
\hline $32-33 . \ldots \ldots \ldots \ldots$ & 0.005296 & 93,940 & 497 & 93,691 & $3,736,919$ & 39.8 \\
\hline $33-34 \ldots \ldots \ldots \ldots$ & 0.005539 & 93,442 & 518 & 93,184 & $3,643,228$ & 39.0 \\
\hline $34-35 .$. & 0.005695 & 92,925 & 529 & 92,660 & $3,550,044$ & 38.2 \\
\hline $35-36$. & 0.005853 & 92,396 & 541 & 92,125 & $3,457,384$ & 37.4 \\
\hline$\ldots \ldots \ldots$ & 0.006039 & 91,855 & 555 & 91,577 & $3,365,259$ & 36.6 \\
\hline$\ldots \ldots \ldots \ldots$ & 0.006197 & 91,300 & 566 & 91,017 & $3,273,681$ & 35.9 \\
\hline$\ldots \ldots \ldots \ldots$ & 0.006323 & 90,734 & 574 & 90,448 & $3,182,664$ & 35.1 \\
\hline$\ldots \ldots \ldots$ & 0.006442 & 90,161 & 581 & 89,870 & $3,092,216$ & 34.3 \\
\hline 40-41. & 0.006554 & 89,580 & 587 & 89,286 & $3,002,346$ & 33.5 \\
\hline $41-42 \ldots \ldots \ldots \ldots \ldots$ & 0.006720 & 88,993 & 598 & 88,694 & $2,913,060$ & 32.7 \\
\hline $42-43 . \ldots \ldots \ldots \ldots$ & 0.007029 & 88,395 & 621 & 88,084 & $2,824,366$ & 32.0 \\
\hline $43-44 \ldots \ldots \ldots \ldots$ & 0.007526 & 87,773 & 661 & 87,443 & $2,736,282$ & 31.2 \\
\hline $44-45 \ldots \ldots \ldots \ldots$ & 0.008164 & 87,113 & 711 & 86,757 & $2,648,839$ & 30.4 \\
\hline $45-46 . \ldots \ldots \ldots \ldots$ & 0.008853 & 86,402 & 765 & 86,019 & $2,562,082$ & 29.7 \\
\hline $46-47 \ldots \ldots \ldots \ldots$ & 0.009544 & 85,637 & 817 & 85,228 & $2,476,063$ & 28.9 \\
\hline $47-48 \ldots \ldots \ldots \ldots$ & 0.010264 & 84,819 & 871 & 84,384 & $2,390,835$ & 28.2 \\
\hline $48-49 . \ldots \ldots \ldots \ldots$ & 0.011010 & 83,949 & 924 & 83,487 & $2,306,451$ & 27.5 \\
\hline $49-50 \ldots \ldots \ldots \ldots$ & 0.011782 & 83,024 & 978 & 82,535 & 2,222,964 & 26.8 \\
\hline $50-51 \ldots \ldots \ldots \ldots$ & 0.012582 & 82,046 & 1,032 & 81,530 & $2,140,429$ & 26.1 \\
\hline $51-52 \ldots \ldots \ldots \ldots \ldots$ & 0.013396 & 81,014 & 1,085 & 80,471 & $2,058,898$ & 25.4 \\
\hline $52-53 \ldots \ldots \ldots \ldots$ & 0.014186 & 79,929 & 1,134 & 79,362 & $1,978,427$ & 24.8 \\
\hline $53-54 \ldots \ldots \ldots \ldots$ & 0.014912 & 78,795 & 1,175 & 78,207 & $1,899,065$ & 24.1 \\
\hline $54-55 \ldots \ldots \ldots \ldots$ & 0.015575 & 77,620 & 1,209 & 77,015 & $1,820,858$ & 23.5 \\
\hline $55-56 \ldots \ldots \ldots \ldots$ & 0.016192 & 76,411 & 1,237 & 75,792 & $1,743,843$ & 22.8 \\
\hline $56-57 \ldots \ldots \ldots \ldots \ldots$ & 0.016808 & 75,174 & 1,264 & 74,542 & $1,668,051$ & 22.2 \\
\hline $57-58 \ldots \ldots \ldots \ldots$ & 0.017463 & 73,910 & 1,291 & 73,265 & $1,593,509$ & 21.6 \\
\hline 58-59. . & 0.018210 & 72,619 & 1,322 & 71,958 & $1,520,244$ & 20.9 \\
\hline $59-60 \ldots \ldots \ldots \ldots$ & 0.019063 & 71,297 & 1,359 & 70,617 & $1,448,286$ & 20.3 \\
\hline
\end{tabular}


Table 4. Life table for non-Hispanic American Indian or Alaska Native males: United States, 2019—Con.

\begin{tabular}{|c|c|c|c|c|c|c|}
\hline & $\begin{array}{c}\text { Probability of dying } \\
\text { between ages } \\
x \text { and } x+1\end{array}$ & $\begin{array}{c}\text { Number surviving } \\
\text { to age } x\end{array}$ & $\begin{array}{c}\text { Number dying } \\
\text { between ages } x \text { and } \\
x+1\end{array}$ & $\begin{array}{c}\text { Person-years lived } \\
\text { between ages } \\
x \text { and } x+1\end{array}$ & $\begin{array}{l}\text { Total number of } \\
\text { person-years lived } \\
\text { above age } x\end{array}$ & $\begin{array}{c}\text { Expectation of life } \\
\text { at age } x\end{array}$ \\
\hline Age (years) & $q_{x}$ & $I_{x}$ & $d_{x}$ & $L_{x}$ & $T_{x}$ & $e_{x}$ \\
\hline$\ldots \ldots \ldots$ & 0.019970 & 69,938 & 1,397 & 69,239 & $1,377,668$ & 19.7 \\
\hline $61-62 .$. & 0.020916 & 68,541 & 1,434 & 67,824 & $1,308,429$ & 19.1 \\
\hline 62-63.. & 0.021976 & 67,108 & 1,475 & 66,370 & $1,240,605$ & 18.5 \\
\hline $63-64 \ldots \ldots \ldots \ldots$ & 0.023171 & 65,633 & 1,521 & 64,872 & $1,174,234$ & 17.9 \\
\hline $64-65 \ldots \ldots \ldots \ldots$ & 0.024494 & 64,112 & 1,570 & 63,327 & $1,109,362$ & 17.3 \\
\hline $65-66 .$. & 0.025971 & 62,542 & 1,624 & 61,729 & $1,046,035$ & 16.7 \\
\hline $66-67$. & 0.027551 & 60,917 & 1,678 & 60,078 & 984,306 & 16.2 \\
\hline 67-68. . & 0.029117 & 59,239 & 1,725 & 58,377 & 924,228 & 15.6 \\
\hline$\ldots \ldots \ldots$ & 0.030558 & 57,514 & 1,758 & 56,635 & 865,851 & 15.1 \\
\hline $69-70 \ldots \ldots \ldots \ldots$ & 0.031888 & 55,757 & 1,778 & 54,868 & 809,216 & 14.5 \\
\hline 70-71. . & 0.033283 & 53,979 & 1,797 & 53,080 & 754,348 & 14.0 \\
\hline $71-72$. & 0.034815 & 52,182 & 1,817 & 51,274 & 701,268 & 13.4 \\
\hline$\ldots \ldots \ldots \ldots$ & 0.036372 & 50,365 & 1,832 & 49,449 & 649,994 & 12.9 \\
\hline $73-74 \ldots \ldots \ldots \ldots$ & 0.037984 & 48,534 & 1,844 & 47,612 & 600,545 & 12.4 \\
\hline $74-75 \ldots \ldots \ldots \ldots$ & 0.039750 & 46,690 & 1,856 & 45,762 & 552,933 & 11.8 \\
\hline $75-76 \ldots \ldots \ldots \ldots$ & 0.041555 & 44,834 & 1,863 & 43,903 & 507,171 & 11.3 \\
\hline $76-77 .$. & 0.043668 & 42,971 & 1,876 & 42,033 & 463,268 & 10.8 \\
\hline$\ldots \ldots \ldots \ldots$ & 0.046720 & 41,095 & 1,920 & 40,135 & 421,235 & 10.3 \\
\hline $78-79 \ldots \ldots \ldots \ldots$ & 0.051163 & 39,175 & 2,004 & 38,172 & 381,101 & 9.7 \\
\hline $79-80 \ldots \ldots \ldots \ldots$ & 0.056873 & 37,170 & 2,114 & 36,113 & 342,928 & 9.2 \\
\hline $80-81 \ldots \ldots \ldots \ldots$ & 0.063774 & 35,056 & 2,236 & 33,938 & 306,815 & 8.8 \\
\hline $81-82 \ldots$ & 0.070268 & 32,821 & 2,306 & 31,667 & 272,877 & 8.3 \\
\hline $82-83 \ldots \ldots \ldots \ldots$ & 0.075730 & 30,514 & 2,311 & 29,359 & 241,209 & 7.9 \\
\hline $83-84 \ldots \ldots \ldots \ldots$ & 0.080249 & 28,204 & 2,263 & 27,072 & 211,850 & 7.5 \\
\hline $84-85 \ldots \ldots \ldots \ldots$ & 0.085310 & 25,940 & 2,213 & 24,834 & 184,778 & 7.1 \\
\hline $85-86 \ldots \ldots \ldots \ldots \ldots$ & 0.092185 & 23,727 & 2,187 & 22,634 & 159,945 & 6.7 \\
\hline $86-87 \ldots \ldots \ldots \ldots$ & 0.098564 & 21,540 & 2,123 & 20,478 & 137,311 & 6.4 \\
\hline $87-88 \ldots \ldots \ldots \ldots$ & 0.107101 & 19,417 & 2,080 & 18,377 & 116,833 & 6.0 \\
\hline $88-89 \ldots \ldots \ldots \ldots$ & 0.116193 & 17,337 & 2,014 & 16,330 & 98,456 & 5.7 \\
\hline $89-90 \ldots \ldots \ldots \ldots$ & 0.125842 & 15,323 & 1,928 & 14,359 & 82,125 & 5.4 \\
\hline $90-91 \ldots \ldots \ldots \ldots$. & 0.136041 & 13,395 & 1,822 & 12,483 & 67,767 & 5.1 \\
\hline $91-92 \ldots \ldots \ldots \ldots$ & 0.146775 & 11,572 & 1,699 & 10,723 & 55,283 & 4.8 \\
\hline $92-93 \ldots \ldots \ldots \ldots$ & 0.158020 & 9,874 & 1,560 & 9,094 & 44,560 & 4.5 \\
\hline $93-94 \ldots \ldots \ldots \ldots$ & 0.169741 & 8,314 & 1,411 & 7,608 & 35,466 & 4.3 \\
\hline $94-95 \ldots \ldots \ldots \ldots$ & 0.181893 & 6,902 & 1,256 & 6,275 & 27,858 & 4.0 \\
\hline $95-96 \ldots \ldots \ldots \ldots$ & 0.194422 & 5,647 & 1,098 & 5,098 & 21,584 & 3.8 \\
\hline $96-97 \ldots \ldots \ldots \ldots$ & 0.207262 & 4,549 & 943 & 4,078 & 16,486 & 3.6 \\
\hline $97-98 \ldots \ldots \ldots \ldots$ & 0.220337 & 3,606 & 795 & 3,209 & 12,408 & 3.4 \\
\hline $98-99 . \ldots \ldots \ldots \ldots$ & 0.233565 & 2,812 & 657 & 2,483 & 9,199 & 3.3 \\
\hline $99-100 \ldots \ldots \ldots \ldots$ & 0.246856 & 2,155 & 532 & 1,889 & 6,716 & 3.1 \\
\hline 100 and over .......... & 1.000000 & 1,623 & 1,623 & 4,827 & 4,827 & 3.0 \\
\hline
\end{tabular}

NOTE: This life table is based on death rates that have been adjusted for race and Hispanic-origin misclassification on death certificates.

SOURCE: National Center for Health Statistics, National Vital Statistics System, Mortality. 
Table 5. Life table for non-Hispanic American Indian or Alaska Native females: United States, 2019

\begin{tabular}{|c|c|c|c|c|c|c|}
\hline & $\begin{array}{c}\text { Probability of dying } \\
\text { between ages } \\
x \text { and } x+1\end{array}$ & $\begin{array}{l}\text { Number surviving } \\
\text { to age } x\end{array}$ & $\begin{array}{c}\text { Number dying } \\
\text { between ages } x \text { and } \\
x+1\end{array}$ & $\begin{array}{c}\text { Person-years lived } \\
\text { between ages } \\
x \text { and } x+1\end{array}$ & $\begin{array}{l}\text { Total number of } \\
\text { person-years lived } \\
\text { above age } x\end{array}$ & $\begin{array}{l}\text { Expectation of life } \\
\text { at age } x\end{array}$ \\
\hline Age (years) & $q_{x}$ & $I_{x}$ & $d_{x}$ & $L_{x}$ & $T_{x}$ & $e_{x}$ \\
\hline$\ldots \ldots \ldots$ & 0.007062 & 100,000 & 706 & 99,442 & $7,495,074$ & 75.0 \\
\hline $1-2 \ldots$ & 0.000907 & 99,294 & 90 & 99,249 & $7,395,632$ & 74.5 \\
\hline$\ldots \ldots \ldots \ldots$ & 0.000681 & 99,204 & 68 & 99,170 & $7,296,383$ & 73.5 \\
\hline$\ldots \ldots \ldots$ & 0.000669 & 99,136 & 66 & 99,103 & $7,197,213$ & 72.6 \\
\hline $4-5 \ldots \ldots \ldots \ldots \ldots$ & 0.000396 & 99,070 & 39 & 99,050 & $7,098,110$ & 71.6 \\
\hline $5-6 \ldots \ldots \ldots \ldots \ldots$ & 0.000349 & 99,031 & 35 & 99,013 & $6,999,060$ & 70.7 \\
\hline $6-7 \ldots \ldots \ldots \ldots \ldots$ & 0.000287 & 98,996 & 28 & 98,982 & $6,900,046$ & 69.7 \\
\hline $7-8 \ldots \ldots \ldots \ldots \ldots$ & 0.000233 & 98,968 & 23 & 98,956 & $6,801,064$ & 68.7 \\
\hline 8-9. . & 0.000174 & 98,945 & 17 & 98,936 & $6,702,108$ & 67.7 \\
\hline $9-10 \ldots \ldots \ldots \ldots \ldots$ & 0.000113 & 98,927 & 11 & 98,922 & $6,603,172$ & 66.7 \\
\hline $10-11 \ldots \ldots \ldots \ldots$ & 0.000063 & 98,916 & 6 & 98,913 & $6,504,250$ & 65.8 \\
\hline $11-12 \ldots \ldots \ldots \ldots \ldots$ & 0.000049 & 98,910 & 5 & 98,908 & $6,405,337$ & 64.8 \\
\hline $12-13$. & 0.000100 & 98,905 & 10 & 98,900 & $6,306,429$ & 63.8 \\
\hline 13-14. . & 0.000232 & 98,895 & 23 & 98,884 & $6,207,529$ & 62.8 \\
\hline $14-15 \ldots \ldots \ldots \ldots \ldots$ & 0.000423 & 98,872 & 42 & 98,851 & $6,108,645$ & 61.8 \\
\hline $15-16 \ldots \ldots \ldots \ldots$ & 0.000649 & 98,830 & 64 & 98,798 & $6,009,794$ & 60.8 \\
\hline $16-17 \ldots \ldots \ldots \ldots \ldots$ & 0.000864 & 98,766 & 85 & 98,724 & $5,910,996$ & 59.8 \\
\hline $17-18$. & 0.001038 & 98,681 & 102 & 98,630 & $5,812,272$ & 58.9 \\
\hline $18-19$. & 0.001145 & 98,579 & 113 & 98,522 & $5,713,642$ & 58.0 \\
\hline $19-20 .$. & 0.001203 & 98,466 & 118 & 98,407 & $5,615,120$ & 57.0 \\
\hline $20-21 \ldots \ldots \ldots \ldots \ldots$ & 0.001261 & 98,347 & 124 & 98,285 & $5,516,713$ & 56.1 \\
\hline $21-22 \ldots \ldots \ldots \ldots \ldots$ & 0.001337 & 98,223 & 131 & 98,158 & $5,418,428$ & 55.2 \\
\hline 22-23. . & 0.001406 & 98,092 & 138 & 98,023 & $5,320,270$ & 54.2 \\
\hline 23-24. . & 0.001466 & 97,954 & 144 & 97,882 & $5,222,247$ & 53.3 \\
\hline $24-25 \ldots \ldots \ldots \ldots$ & 0.001524 & 97,811 & 149 & 97,736 & $5,124,365$ & 52.4 \\
\hline $25-26 \ldots \ldots \ldots \ldots \ldots$ & 0.001565 & 97,661 & 153 & 97,585 & $5,026,629$ & 51.5 \\
\hline $26-27 \ldots \ldots \ldots \ldots \ldots$ & 0.001620 & 97,509 & 158 & 97,430 & $4,929,044$ & 50.5 \\
\hline $27-28 \ldots \ldots \ldots \ldots$ & 0.001737 & 97,351 & 169 & 97,266 & $4,831,614$ & 49.6 \\
\hline $28-29 \ldots \ldots \ldots \ldots$ & 0.001944 & 97,181 & 189 & 97,087 & $4,734,348$ & 48.7 \\
\hline $29-30 \ldots \ldots \ldots \ldots \ldots$ & 0.002229 & 96,993 & 216 & 96,885 & $4,637,261$ & 47.8 \\
\hline $30-31 \ldots \ldots \ldots \ldots$ & 0.002567 & 96,776 & 248 & 96,652 & $4,540,377$ & 46.9 \\
\hline $31-32 \ldots \ldots \ldots \ldots \ldots$ & 0.002904 & 96,528 & 280 & 96,388 & $4,443,724$ & 46.0 \\
\hline $32-33 . \ldots \ldots \ldots \ldots$ & 0.003203 & 96,248 & 308 & 96,094 & $4,347,337$ & 45.2 \\
\hline $33-34 \ldots \ldots \ldots \ldots$ & 0.003413 & 95,939 & 327 & 95,776 & $4,251,243$ & 44.3 \\
\hline $34-35 \ldots \ldots \ldots \ldots$ & 0.003549 & 95,612 & 339 & 95,442 & $4,155,467$ & 43.5 \\
\hline $35-36 \ldots \ldots \ldots \ldots$ & 0.003681 & 95,273 & 351 & 95,097 & $4,060,025$ & 42.6 \\
\hline $36-37 \ldots \ldots \ldots \ldots$ & 0.003838 & 94,922 & 364 & 94,740 & $3,964,927$ & 41.8 \\
\hline $37-38 \ldots \ldots \ldots \ldots$ & 0.003982 & 94,558 & 377 & 94,369 & $3,870,188$ & 40.9 \\
\hline $38-39 . \ldots \ldots \ldots \ldots$ & 0.004115 & 94,181 & 388 & 93,987 & $3,775,818$ & 40.1 \\
\hline $39-40 \ldots \ldots \ldots \ldots$ & 0.004252 & 93,794 & 399 & 93,594 & $3,681,831$ & 39.3 \\
\hline $40-41 \ldots \ldots \ldots \ldots$ & 0.004391 & 93,395 & 410 & 93,190 & $3,588,237$ & 38.4 \\
\hline $41-42 \ldots \ldots \ldots \ldots$ & 0.004558 & 92,985 & 424 & 92,773 & $3,495,047$ & 37.6 \\
\hline $42-43$. & 0.004795 & 92,561 & 444 & 92,339 & $3,402,274$ & 36.8 \\
\hline $43-44 \ldots \ldots \ldots \ldots$ & 0.005121 & 92,117 & 472 & 91,881 & $3,309,935$ & 35.9 \\
\hline $44-45 \ldots \ldots \ldots \ldots$ & 0.005507 & 91,645 & 505 & 91,393 & $3,218,054$ & 35.1 \\
\hline $45-46 \ldots \ldots \ldots \ldots$ & 0.005908 & 91,141 & 538 & 90,871 & $3,126,661$ & 34.3 \\
\hline $46-47 \ldots \ldots \ldots \ldots$ & 0.006308 & 90,602 & 571 & 90,316 & $3,035,789$ & 33.5 \\
\hline $47-48$. & 0.006726 & 90,031 & 606 & 89,728 & $2,945,473$ & 32.7 \\
\hline $48-49 . \ldots \ldots \ldots \ldots$ & 0.007169 & 89,425 & 641 & 89,105 & $2,855,745$ & 31.9 \\
\hline $49-50 \ldots \ldots \ldots \ldots$ & 0.007633 & 88,784 & 678 & 88,445 & $2,766,640$ & 31.2 \\
\hline $50-51 \ldots \ldots \ldots \ldots$ & 0.008131 & 88,106 & 716 & 87,748 & $2,678,195$ & 30.4 \\
\hline $51-52 \ldots \ldots \ldots \ldots$ & 0.008629 & 87,390 & 754 & 87,013 & $2,590,447$ & 29.6 \\
\hline $52-53$. & 0.009063 & 86,636 & 785 & 86,243 & $2,503,434$ & 28.9 \\
\hline $53-54 \ldots \ldots \ldots$ & 0.009395 & 85,851 & 807 & 85,447 & $2,417,191$ & 28.2 \\
\hline $54-55 \ldots \ldots \ldots \ldots$ & 0.009658 & 85,044 & 821 & 84,634 & $2,331,743$ & 27.4 \\
\hline $55-56 \ldots \ldots \ldots \ldots$ & 0.009867 & 84,223 & 831 & 83,807 & $2,247,110$ & 26.7 \\
\hline $56-57 \ldots \ldots \ldots \ldots$ & 0.010116 & 83,392 & 844 & 82,970 & $2,163,302$ & 25.9 \\
\hline $57-58 \ldots \ldots \ldots \ldots$ & 0.010500 & 82,548 & 867 & 82,115 & $2,080,332$ & 25.2 \\
\hline $58-59 \ldots \ldots \ldots \ldots$ & 0.011086 & 81,681 & 905 & 81,229 & $1,998,218$ & 24.5 \\
\hline $59-60 \ldots \ldots \ldots \ldots$ & 0.011835 & 80,776 & 956 & 80,298 & $1,916,989$ & 23.7 \\
\hline
\end{tabular}


Table 5. Life table for non-Hispanic American Indian or Alaska Native females: United States, 2019—Con.

\begin{tabular}{|c|c|c|c|c|c|c|}
\hline & $\begin{array}{c}\text { Probability of dying } \\
\text { between ages } \\
x \text { and } x+1\end{array}$ & $\begin{array}{c}\text { Number surviving } \\
\text { to age } x\end{array}$ & $\begin{array}{c}\text { Number dying } \\
\text { between ages } x \text { and } \\
x+1\end{array}$ & $\begin{array}{c}\text { Person-years lived } \\
\text { between ages } \\
x \text { and } x+1\end{array}$ & $\begin{array}{l}\text { Total number of } \\
\text { person-years lived } \\
\text { above age } x\end{array}$ & $\begin{array}{c}\text { Expectation of life } \\
\text { at age } x\end{array}$ \\
\hline Age (years) & $q_{x}$ & $I_{x}$ & $d_{x}$ & $L_{x}$ & $T_{x}$ & $e_{x}$ \\
\hline 60-61. . & 0.012681 & 79,820 & 1,012 & 79,314 & $1,836,691$ & 23.0 \\
\hline $61-62 \ldots \ldots \ldots \ldots \ldots$ & 0.013512 & 78,808 & 1,065 & 78,275 & $1,757,377$ & 22.3 \\
\hline $62-63 . \ldots \ldots \ldots \ldots$ & 0.014286 & 77,743 & 1,111 & 77,188 & $1,679,102$ & 21.6 \\
\hline $63-64 \ldots \ldots \ldots \ldots \ldots$ & 0.014949 & 76,632 & 1,146 & 76,059 & $1,601,914$ & 20.9 \\
\hline $64-65 \ldots$ & 0.015550 & 75,487 & 1,174 & 74,900 & $1,525,855$ & 20.2 \\
\hline $65-66 \ldots$ & 0.016185 & 74,313 & 1,203 & 73,711 & $1,450,955$ & 19.5 \\
\hline$\ldots \ldots \ldots$ & 0.016949 & 73,110 & 1,239 & 72,491 & $1,377,243$ & 18.8 \\
\hline $67-68 . \ldots \ldots \ldots \ldots$ & 0.017848 & 71,871 & 1,283 & 71,230 & $1,304,753$ & 18.2 \\
\hline $68-69 \ldots$ & 0.018920 & 70,588 & 1,336 & 69,920 & $1,233,523$ & 17.5 \\
\hline $69-70 .$. & 0.020158 & 69,253 & 1,396 & 68,555 & $1,163,603$ & 16.8 \\
\hline $70-71 \ldots$ & 0.021532 & 67,857 & 1,461 & 67,126 & $1,095,048$ & 16.1 \\
\hline $71-72 \ldots \ldots \ldots \ldots \ldots$ & 0.023046 & 66,396 & 1,530 & 65,630 & $1,027,922$ & 15.5 \\
\hline $72-73 \ldots \ldots \ldots \ldots$ & 0.024752 & 64,865 & 1,606 & 64,063 & 962,292 & 14.8 \\
\hline $73-74 \ldots \ldots \ldots \ldots \ldots$ & 0.026701 & 63,260 & 1,689 & 62,415 & 898,229 & 14.2 \\
\hline $74-75 \ldots$ & 0.028941 & 61,571 & 1,782 & 60,680 & 835,814 & 13.6 \\
\hline $75-76 \ldots \ldots \ldots \ldots$ & 0.031552 & 59,789 & 1,886 & 58,846 & 775,134 & 13.0 \\
\hline $76-77 \ldots \ldots \ldots \ldots$ & 0.034542 & 57,902 & 2,000 & 56,902 & 716,288 & 12.4 \\
\hline $77-78 \ldots \ldots \ldots \ldots$ & 0.037820 & 55,902 & 2,114 & 54,845 & 659,386 & 11.8 \\
\hline $78-79 \ldots \ldots \ldots \ldots$ & 0.041229 & 53,788 & 2,218 & 52,679 & 604,541 & 11.2 \\
\hline $79-80 \ldots \ldots \ldots \ldots \ldots$ & 0.044720 & 51,570 & 2,306 & 50,417 & 551,862 & 10.7 \\
\hline $80-81 \ldots \ldots \ldots \ldots$ & 0.048233 & 49,264 & 2,376 & 48,076 & 501,444 & 10.2 \\
\hline $81-82 \ldots \ldots \ldots \ldots \ldots$ & 0.052070 & 46,888 & 2,441 & 45,667 & 453,368 & 9.7 \\
\hline $82-83 \ldots \ldots \ldots \ldots$ & 0.056584 & 44,447 & 2,515 & 43,189 & 407,701 & 9.2 \\
\hline $83-84 \ldots \ldots \ldots \ldots \ldots$ & 0.061683 & 41,932 & 2,586 & 40,638 & 364,512 & 8.7 \\
\hline $84-85 \ldots$ & 0.066631 & 39,345 & 2,622 & 38,034 & 323,873 & 8.2 \\
\hline $85-86 \ldots \ldots \ldots \ldots \ldots$ & 0.072644 & 36,724 & 2,668 & 35,390 & 285,839 & 7.8 \\
\hline $86-87 \ldots \ldots \ldots \ldots \ldots$ & 0.078627 & 34,056 & 2,678 & 32,717 & 250,449 & 7.4 \\
\hline $87-88 \ldots \ldots \ldots \ldots$ & 0.085960 & 31,378 & 2,697 & 30,029 & 217,732 & 6.9 \\
\hline $88-89 \ldots$ & 0.093848 & 28,681 & 2,692 & 27,335 & 187,703 & 6.5 \\
\hline $89-90 \ldots \ldots \ldots \ldots$ & 0.102308 & 25,989 & 2,659 & 24,660 & 160,368 & 6.2 \\
\hline $90-91 \ldots \ldots \ldots \ldots$ & 0.111350 & 23,330 & 2,598 & 22,031 & 135,708 & 5.8 \\
\hline $91-92 \ldots \ldots \ldots \ldots \ldots$ & 0.120979 & 20,733 & 2,508 & 19,478 & 113,676 & 5.5 \\
\hline $92-93 \ldots \ldots \ldots \ldots \ldots$ & 0.131191 & 18,224 & 2,391 & 17,029 & 94,198 & 5.2 \\
\hline $93-94 \ldots \ldots \ldots \ldots \ldots$ & 0.141975 & 15,833 & 2,248 & 14,709 & 77,169 & 4.9 \\
\hline $94-95 \ldots \ldots \ldots \ldots$ & 0.153309 & 13,585 & 2,083 & 12,544 & 62,460 & 4.6 \\
\hline $95-96 \ldots \ldots \ldots \ldots$ & 0.165161 & 11,503 & 1,900 & 10,553 & 49,916 & 4.3 \\
\hline $96-97 \ldots \ldots \ldots \ldots \ldots$ & 0.177487 & 9,603 & 1,704 & 8,751 & 39,363 & 4.1 \\
\hline $97-98 \ldots \ldots \ldots \ldots \ldots$ & 0.190233 & 7,899 & 1,503 & 7,147 & 30,612 & 3.9 \\
\hline $98-99 \ldots \ldots \ldots \ldots$ & 0.203332 & 6,396 & 1,301 & 5,746 & 23,465 & 3.7 \\
\hline $99-100 \ldots \ldots \ldots \ldots$ & 0.216710 & 5,095 & 1,104 & 4,543 & 17,719 & 3.5 \\
\hline 100 and over ........ & 1.000000 & 3,991 & 3,991 & 13,176 & 13,176 & 3.3 \\
\hline
\end{tabular}

NOTE: This life table is based on death rates that have been adjusted for race and Hispanic-origin misclassification on death certificates.

SOURCE: National Center for Health Statistics, National Vital Statistics System, Mortality. 


\section{Technical Notes}

\section{Data}

\section{Vital statistics data}

Death counts used to calculate the mortality estimates presented in this report are final numbers of deaths for 2019 collected from death certificates filed in state vital statistics offices and reported to the National Center for Health Statistics (NCHS) as part of the National Vital Statistics System (NVSS). Hispanic origin and race are reported separately on the death certificate.

Beginning with the 2018 data year, all 50 states and the District of Columbia reported deaths based on the 2003 revision of the U.S. Standard Certificate of Death for the entire year (14). The revision is based on the 1997 Office of Management and Budget (OMB) standards (18). The 1997 standards allow individuals to report more than one race and increased the race choices from four to five by separating the Asian and Pacific Islander groups. The Hispanic category did not change, remaining consistent with previous reports. The Hispanic origin and race groups in this report follow the 1997 standards and combine Hispanic origin and race to produce the following categories: non-Hispanic Native American or Alaska Native (AIAN), non-Hispanic white, non-Hispanic black, and Hispanic.

\section{Census population data}

The population data used to estimate the death rates and life tables for 2019 shown in this report are postcensal population estimates based on the 2010 decennial census and are available from the U.S. Census website, https://www2.census.gov/ programs-surveys/popest/datasets/2010-2019/national/asrh/ nc-est2019-alldata-r-file20.csv. Reflecting the 1997 OMB guidelines on race and ethnicity reporting, the 2010 census included an option for individuals to report more than one race and provided for the reporting of Asian persons separately from Native Hawaiian or other Pacific Islander persons (18).

\section{American Indian or Alaska Native Census-Mortality- linked data}

Under a collaborative agreement between NCHS and the U.S. Census Bureau, an extract of the 2010 Census Edited File (CEF)-Census Unedited File (CUF) Match File containing records for persons classified as AIAN alone or in combination with another race in the 2010 decennial census were linked to the National Death Index (NDI) to identify decedents for the period April 1, 2010, to December 31, 2011. The CUF file contains final housing and population counts after count imputation procedures were applied and were the final counts for the 2010 Census used to calculate apportionment of the U.S. House of Representatives. The CEF file was the result of the demographic edits applied to the CUF. The CEF-CUF Match File is a linkage of the CUF and CEF by person-record used to ascertain the effects of the edits. The CEF-CUF Match AIAN Extract File used for this study included records with the minimum required matching identifiers, such as names and dates of birth, for submission to NDI (16). A total of $4,746,003$ original records were submitted to NDI and 34,366 deaths for the period April 1, 2010, through December 31, 2011, were identified. Decedent records were linked to corresponding NVSS death certificates. Technical Notes Table I presents a breakdown of CEF-CUF Match AIAN extract records by race, Hispanic origin, and vital status.

Table I. CEF-CUF Match AIAN Extract-Mortality-Linked Data

\begin{tabular}{|c|c|c|}
\hline Race and Hispanic origin & Living & Deaths \\
\hline$\ldots \ldots \ldots \ldots \ldots \ldots \ldots$ & $4,746,003$ & 34,366 \\
\hline AIAN alone . . . . . . . . . . . & $2,633,422$ & 20,301 \\
\hline AIAN in combination. ..... & $2,112,581$ & 14,065 \\
\hline Non-Hispanic AIAN alone . . . . . . . . . . . & $1,984,565$ & 18,278 \\
\hline Non-Hispanic AIAN in combination. . . . . . & $1,627,651$ & 12,798 \\
\hline Hispanic AIAN alone . . . . . . . . . . . . . . . & 648,857 & 2,023 \\
\hline Hispanic AIAN in combination . . . . . . . & 484,930 & 1,267 \\
\hline
\end{tabular}

NOTE: AIAN is American Indian or Alaska Native.

SOURCE: National Center for Health Statistics, National Vital Statistics System, Mortality.

\section{Methods}

\section{Classification ratios}

The 34,366 CEF-CUF Match AIAN Extract-Mortality Linked Data decedent records were used to develop correction factors (classification ratios) to correct for race and Hispanicorigin misclassification on death certificates for the AIAN population. Classification ratios are defined as the ratio of CEF-CUF Match AIAN Extract File race and Hispanic-origin counts to death certificate counts for the sample of decedents in the CEF-CUF Match AIAN Extract-Mortality Data File. For example, the classification ratio for the non-Hispanic AIAN population is estimated as the number of decedents identified as non-Hispanic AIAN on the CEF-CUF Match AIAN Extract Data File to the number identified as non-Hispanic AIAN on the death certificate. This is basically a ratio of row to column totals in a bivariate table of CEF-CUF Match AIAN Extract File (row) by death certificate (column) classification. It can be interpreted as the net difference in assignment of non-Hispanic AIAN between the two data collection systems. The classification ratios can be easily interpreted as adjustment factors to correct for the bias found on death certificates (1).

The classification ratios were estimated by decedents' sex, age, and cause of death. The variables used for analyses were derived from the death certificate and include two age groupings $(0,1-4,5-14,15-24,25-34,35-44,45-54,55-64,65-74$, $75-84$, and 85 and over; and 0-24, 25-44, 45-64, 65-84, and 85 and over), sex, and the 201915 leading causes of death. 
Table II. Classification ratios, by sex and age for the non-Hispanic American Indian or Alaska Native population

\begin{tabular}{|c|c|c|c|}
\hline Age group (years) & Total (standard error) & Male (standard error) & Female (standard error) \\
\hline All ages ${ }^{1}$. & $1.3354(0.007)$ & $1.3488(0.010)$ & $1.3197(0.011)$ \\
\hline Under 1. & $0.9630(0.132)$ & $0.9444(0.181)$ & $1.0000(0.161)$ \\
\hline $1-4 \ldots \ldots$ & $1.1618(0.080)$ & $1.2857(0.138)$ & $1.0303(0.082)$ \\
\hline $5-14$ & $1.0990(0.066)$ & $1.0806(0.077)$ & $1.1282(0.119)$ \\
\hline 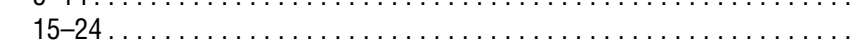 & $1.1462(0.029)$ & $1.1201(0.033)$ & $1.2190(0.056)$ \\
\hline$\ldots \ldots \ldots \ldots \ldots \ldots \ldots$ & $1.1375(0.025)$ & $1.1557(0.032)$ & $1.1033(0.040)$ \\
\hline $35-44$. & $1.1799(0.022)$ & $1.1815(0.027)$ & $1.1772(0.036)$ \\
\hline $45-54$. & $1.3915(0.021)$ & $1.3913(0.027)$ & $1.3916(0.033)$ \\
\hline$\ldots \ldots \ldots \ldots \ldots$ & $1.4281(0.019)$ & $1.4547(0.026)$ & $1.3917(0.029)$ \\
\hline $65-74$. & $1.3654(0.017)$ & $1.4244(0.025)$ & $1.2980(0.023)$ \\
\hline $75-84 \ldots \ldots$ & $1.3099(0.017)$ & $1.3367(0.025)$ & $1.2852(0.022)$ \\
\hline 85 and over. . . . & $1.3862(0.022)$ & $1.3727(0.036)$ & $1.3944(0.028)$ \\
\hline
\end{tabular}

${ }^{1}$ Includes ages not stated.

SOURCE: National Center for Health Statistics, National Vital Statistics System, Mortality.

Classification ratios and standard errors are calculated as follows (see Tables II-III for classification ratios):

$$
C R_{X}=\frac{S R_{X}}{D R_{X}}
$$

$\operatorname{SE}\left(C R_{X}\right)=$

$\sqrt{\frac{1}{D R_{X}^{2}} \cdot\left\{\operatorname{Var}\left(S R_{X}\right)-2 \cdot C R_{X} \cdot \operatorname{Cov}\left(S R_{X}, D R_{X}\right)+C R_{X}^{2} \cdot \operatorname{Var}\left(D R_{X}\right)\right\}}$

where $x$ denotes the age group, $S R_{x}$ is self-reported race in census data, and $D R_{x}$ is proxy reported race on death certificates.

\section{Adjusted death counts, death rates, and standard errors (SE)}

Age-specific death counts and rates, and age-adjusted death rates adjusted for race and Hispanic-origin misclassification were estimated as follows:

Age-Specific Death Count $=D_{X} \cdot C R_{X}$

Age-Specific Death Rate $(\operatorname{ASDRx})=R_{X}=\frac{D_{X}}{P_{X}} \cdot C R_{X}$

Age-Adjusted Death Rate $($ ADR $)=$

$$
R^{\prime}=\sum_{X}\left[\left(\frac{D_{X}}{P_{X}} \cdot C R_{X}\right) \cdot W_{X}\right]
$$

$$
\begin{aligned}
& S E\left(R_{X}\right)= \\
& \sqrt{\left.\left[C R_{X}^{2} \cdot S E\left(D_{X}\right)^{2}\right)+\left(D_{X}^{2} \cdot S E\left(C R_{X}\right)^{2}\right)\right] / P_{X}^{2}} \\
& S E\left(R^{\prime}\right)=\sqrt{\sum_{X}\left[W_{X}^{2} \cdot S E\left(R_{X}\right)^{2}\right]}
\end{aligned}
$$

where $D_{x}$ is the number of deaths in age group $x$ in 2019, $P_{x}$ is the 2019 mid-year population in age group $x, C R_{x}$ is the agespecific classification ratio, and $W_{x}$ is the age-specific weight based on the U.S. 2000 standard population (19). Age-specific death counts, $R_{x}$, and $R^{\prime}$, adjusted for misclassification, were estimated by sex and cause of death.

\section{Life tables}

\section{Adjustments for unknown age}

An adjustment is made to account for the small proportion of deaths each year for which age is not reported on the death certificate. The number of deaths in each age category is adjusted proportionally to account for those with not-stated ages. The following factor $(F)$ is used to make the adjustment. $F$ is calculated for the total and for each sex group within a racial and ethnic population for which life tables are constructed:

$$
F=\frac{D}{D^{a}}
$$

where $D$ is the total number of deaths and $D^{a}$ is the total number of deaths for which age is stated. Fis then applied by multiplying it by the number of deaths in each age group.

\section{Adjustment for misclassification of Hispanic origin and race on death certificates}

The AIAN Census-Mortality-linked data described above were used to adjust the age-specific number of deaths for aged 1-95 and over for the non-Hispanic AIAN population by sex, as follows:

$$
{ }_{n} D_{x}={ }_{n} D_{x}^{F} \cdot{ }_{n} C R_{x},
$$

where ${ }_{n} D_{x}{ }^{F}$ is the age-specific number of deaths adjusted for unknown age as described above, ${ }_{n} C R_{x}$ are the sex- and age-specific classification ratios used to correct for the misclassification of Hispanic origin and race on death certificates, and ${ }_{n} D_{x}$ are the final age-specific counts of death adjusted for age and Hispanic origin and race misclassification.

Classification ratios for infant deaths are unreliable due to small sample sizes and, as a result, corrections for racial and ethnic misclassification of infant deaths are addressed by using infant death counts and live birth counts from the 2018 and 2019 linked birth/infant death data files rather than the traditional birth and death data files $(20,21)$. In the linked file, each infant death record is linked to its corresponding birth record so that the race and ethnicity of the mother reported on the birth record can be ascribed to the infant death record. As a result, raceand ethnicity-specific infant mortality rates estimated with the 
linked file do not suffer from the problem of racial and ethnic discrepancies between the numerator and denominator of the rate.

\section{Interpolation of $\boldsymbol{P}_{\boldsymbol{x}}$ and $\boldsymbol{D}_{\boldsymbol{x}}$}

Anomalies-both random and those associated with reporting age at death-can be problematic when using vital statistics and census data by single years of age to estimate the probability of death (22). Graduation techniques are often used to eliminate these anomalies and to derive a smooth curve by age. Beers ordinary minimized fifth difference formula is used to obtain smoothed values of population counts $\left(P_{\chi}\right)$ and death counts $\left(D_{x}\right)$ from 5-year age groupings of ${ }_{n} P_{x}$ from aged 0 to 99 and ${ }_{n} D_{x}$ from aged 5 to 99 , and where ${ }_{n}{ }_{n}$. has first been adjusted for not-reported age and Hispanic origin and race misclassification on the death certificate (23).

\section{Calculation of the probability of dying $\left(q_{x}\right)$}

The first step in the calculation of a complete period life table is the estimation of the age-specific probability of dying, $q_{x}$ which is derived from the age-specific death rate, $m_{x}(24)$. In the life table cohort,

$$
m_{x}=\frac{d_{x}}{L_{x}},
$$

where $d_{x}$ is the number of deaths occurring between ages $x$ and $x+1$, and $L_{x}$ is the number of person-years lived by the life table cohort between ages $x$ and $x+1$. The conversion of the agespecific death rate, $m_{x}$, to the age-specific probability of death, $q_{x}$ is as follows:

$$
q_{x}=\frac{m_{x}}{1+\left(1-a_{x}\right) m_{x}}
$$

where $a_{x}$ is the number of person-years lived in the age interval by members of the life table cohort who died in the interval. When the age interval is 1 year, except at infancy, $a_{x}=1 / 2$; in other words, deaths occur on average midway through the age interval. As a result,

$$
q_{x}=\frac{m_{x}}{1+\frac{1}{2} m_{x}} .
$$

Because the complete period life table is based on the agespecific death rates of a current population observed for a specific calendar year, the life table death rate is equivalent to the observed death rates of the current population:

$$
m_{x}=\frac{d_{x}}{L_{x}}=M_{x}=\frac{D_{x}}{P_{x}}
$$

where $D_{x}$ is the Beers smoothed number of deaths adjusted for not-stated age and Hispanic origin and race misclassification on the death certificate (for the Hispanic, non-Hispanic single-race white, and non-Hispanic single-race black populations) and $P_{x}$ is the Beers smoothed population at risk of dying between ages $x$ and $x+1$. Then,

$$
q_{x}=\frac{M_{x}}{1+\frac{1}{2} M_{x}}=\frac{D_{x}}{P_{x}+\frac{1}{2} D_{x}}
$$

This procedure is used to estimate vital statistics agespecific probabilities of death for aged 1-99.

\section{Calculation of $q_{x}$ at age 0}

The higher mortality observed in infancy is associated with a high concentration of deaths occurring at the beginning of the age interval rather than in the middle. As a result, whenever possible it is best to assign deaths to the appropriate birth cohorts. Therefore, the probability of death at birth, $q$ is calculated using a birth cohort method that employs a separation factor $(f)$ defined as the proportion of infant deaths in year $t$ occurring to infants born in the previous year $(t-1)$. The value $f$ is estimated by categorizing infant deaths by date of birth. The probability of death is then calculated as

$$
q_{0}=\frac{D_{0}(1-f)}{B^{t}}+\frac{D_{0}(f)}{B^{t-1}}
$$

where $D_{0}$ is the number of infant deaths adjusted for not-stated age in $2019, B^{t}$ is the number of live births in 2019 , and $B^{t-1}$ is the number of live births in 2018.

\section{Probabilities of dying at the oldest ages}

Due to the unreliability of vital statistics data for the oldest ages, Medicare data is used to supplement vital statistics data for aged 65 and over for the total, non-Hispanic white, and non-Hispanic black populations in the production of national life tables (11). However, it is not possible to use Medicare data for the AIAN population due to inconsistencies in the Medicare race and ethnicity classification system for racial and ethnic populations other than white and black populations $(4,11)$. As a result, it was necessary to use other methods to estimate mortality at the oldest ages for the non-Hispanic AIAN population. The Brass relational logit model was used to estimate mortality for aged 85 and over $(25,26)$. This model is used to estimate the annual U.S. life tables for the Hispanic population and was used to estimate U.S. life tables for the non-Hispanic AIAN population living in Contract Health Service Delivery Area or Tribal Service Delivery Area counties for the period 2007-2009 $(4,11)$.

The Brass relational logit model expresses the age-specific mortality pattern of a population of interest as a function of the age-specific mortality pattern of a standard population and is expressed as:

$$
\bar{Y}_{x}=\alpha+\beta Y_{x}^{s}
$$

where $\bar{Y}_{x}$ is the predicted logit of the probability of death, $q_{x}$ in the population of interest, that is,

$$
\text { logit }\left[q_{x}\right]=\ln \left[\frac{q_{x}}{1-q_{x}}\right]
$$

$Y_{x}^{S}$ is the logit of the probability of death in the standard population, $q_{x}{ }^{S}$, that is,

$$
\text { logit }\left[q_{x}^{S}\right]=\ln \left[\frac{q_{x}^{S}}{1-q_{x}^{S}}\right]
$$

$\alpha$ is the predicted parameter that measures the level of mortality of the population of interest relative to the standard population, and $\beta$ is the predicted parameter that measures the slope of the 
mortality function of the population of interest relative to the standard population (24-26).

A maximum-likelihood generalized linear model estimation procedure is used to fit equation in the age range $45-84$. The resulting predicted parameters $\alpha$ and $\beta$ were then used to estimate the predicted probability of death for aged $85-120$ in the Hispanic population. The value $q_{x}$, was predicted to age 120 in order to estimate the life table population until no survivors remain, as was done for the other population groups. This information is then used to estimate $L_{x}$ for aged $100-120$, which is used to close the table with the age category 100 and over, combined (discussed below).

Predicted $\bar{q}_{x}$ is estimated by transforming its logit, $\bar{Y}_{x}$, back as follows:

$$
\bar{q}_{x}=\frac{\exp \left[\bar{Y}_{x}\right]}{1+\exp \left[\bar{Y}_{x}\right]}=\frac{\exp \left[\alpha+\beta Y_{x}^{S}\right]}{1+\exp \left[\alpha+\beta Y_{x}^{S}\right]} .
$$

To ensure a smooth transition from vital $q_{x}^{V}$ and predicted $\bar{q}_{x}$, the two were blended from aged 80-84 with a graduating process as follows:

$$
q_{x}=\frac{1}{6}\left[(85-x) q_{x}^{v}+(x-79) \bar{q}_{x}\right] .
$$

when $x=80, \ldots, 84$.

Finally, to close the table at aged 100 and over (combined), ${ }_{\infty} q_{100}$ is set equal to 1.0 because all survivors to this age will die at some point in the open-ended age interval. Once $q_{x}$ is obtained for each single year of age, the other life table functions are easily calculated.

\section{Survivor function $\left(I_{x}\right)$}

The life table radix, $I_{0}$, is set at 100,000 . For ages greater than 0 , the number of survivors remaining at exact age $x$ is calculated as

$$
I_{x}=I_{x-1}\left(1-q_{x-1}\right)
$$

\section{Decrement function $\left(d_{x}\right)$}

The number of deaths occurring between ages $x$ and $x+1$ is calculated from the survivor function:

$$
d_{x}=I_{x}-I_{x+1}=I_{x} q_{x}
$$

Note that ${ }_{\infty} d_{100}={ }_{\infty} I_{100}$ because ${ }_{\infty} q_{100}=1.0$.

\section{Person-years lived $\left(L_{x}\right)$}

Person-years lived for aged 1-99 is calculated assuming that the survivor function declines linearly between ages $x$ and $x+1$ This gives the formula

$$
L_{x}=\frac{1}{2}\left(I_{x}+I_{x+1}\right)=I_{x}-\frac{1}{2} d_{x} .
$$

For $x=0$, the separation factor $f$ is used to calculate $L_{0}$ :

$$
L_{0}=f l_{0}+(1-f) l_{1}
$$

Finally, ${ }_{\infty} L_{100}$ is estimated as the sum of the extrapolated $L_{x}$ values for aged 100-120.
Person-years lived at and above age $x\left(T_{x}\right)$

$T_{x}$ is calculated by summing $L_{x}$ values at and above age $x$.

$$
T_{x}=\sum_{x=0}^{\infty} L_{x} .
$$

\section{Life expectancy at age $x\left(e_{x}\right)$}

Life expectancy at exact age $x$ is calculated as

$$
e_{x}=\frac{T_{x}}{I_{x}} .
$$




\begin{tabular}{|c|c|c|c|c|c|c|c|}
\hline \multirow[b]{2}{*}{ Rank $^{1}$} & \multirow{2}{*}{$\begin{array}{l}\text { Sex and cause of death } \\
\text { (based on International Classification of Diseases, 10th Revision) }\end{array}$} & \multicolumn{6}{|c|}{ Age group (years) } \\
\hline & & All ages $^{2}$ & $0-24$ & 25-44 & $45-64$ & $65-84$ & 85 and over \\
\hline \multicolumn{8}{|c|}{ Both sexes } \\
\hline 1 & $\ldots \ldots \ldots \ldots \ldots \ldots(100-109,|111| 13,, \mid 20-151)$ & $1.4397(0.020)$ & $1.0000(0.135)$ & $1.2293(0.066)$ & $1.4854(0.036)$ & $1.4253(0.030)$ & $1.4778(0.048)$ \\
\hline 2 & $\ldots \ldots \ldots \ldots \ldots \ldots \ldots(\mathrm{COO}-\mathrm{C} 97)$ & $1.4059(0.019)$ & $1.2692(0.131)$ & $1.2091(0.084)$ & $1.4674(0.033)$ & $1.3709(0.025)$ & $1.4483(0.066)$ \\
\hline 3 & Accidents (unintentional injuries) . & $1.2481(0.020)$ & $1.1495(0.038)$ & $1.1600(0.029)$ & $1.4469(0.047)$ & $1.2457(0.053)$ & $1.1633(0.099)$ \\
\hline 4 & Chronic liver disease and cirrhosis . & $1.1591(0.023)$ & $1.0000(0.000)$ & $1.0221(0.035)$ & $1.2381(0.033)$ & $1.1207(0.056)$ & $0.8333(0.159)$ \\
\hline 5 & Chronic lower respiratory diseases. . . & $1.5324(0.049)$ & $1.5000(0.661)$ & $1.0656(0.080)$ & $1.1748(0.036)$ & $1.1873(0.029)$ & $1.1809(0.062)$ \\
\hline 6 & Diabetes mellitus $\ldots \ldots \ldots \ldots \ldots$ & $1.1742(0.021)$ & $1.0000(0.000)$ & $1.2500(0.402)$ & $1.7770(0.120)$ & $1.4675(0.060)$ & $1.4337(0.108)$ \\
\hline 7 & Cerebrovascular diseases...... & $1.3679(0.039)$ & $1.1000(0.187)$ & $1.0714(0.105)$ & $1.4324(0.094)$ & $1.3307(0.052)$ & $1.4907(0.097)$ \\
\hline 8 & Intentional self-harm (suicide) $\ldots \ldots \ldots \ldots \ldots \ldots \ldots .\left({ }^{*} \mathrm{U} 03, \mathrm{X} 60-\mathrm{X} 84, \mathrm{Y} 87.0\right)$ & $1.2835(0.042)$ & $1.0507(0.049)$ & $1.2722(0.061)$ & $1.7200(0.144)$ & $1.3000(0.415)$ & $0.0000(0.000)$ \\
\hline 9 & Nephritis, nephrotic syndrome and nephrosis. .... (N00-N07,N17-N19,N25-N27) & $1.2971(0.046)$ & $2.0000(1.581)$ & $1.1000(0.108)$ & $1.3165(0.089)$ & $1.2826(0.063)$ & $1.3333(0.128)$ \\
\hline 10 & 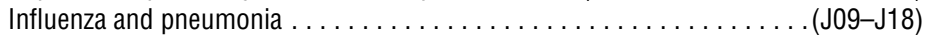 & $1.2755(0.042)$ & $1.2500(0.351)$ & $1.2273(0.135)$ & $1.2877(0.087)$ & $1.2212(0.063)$ & $1.3590(0.087)$ \\
\hline 11 & Alzheimer disease. . . . . . . & $1.3758(0.073)$ & $0.0000(0.000)$ & $0.0000(0.000)$ & $1.0000(0.000)$ & $1.3951(0.103)$ & $1.3659(0.107)$ \\
\hline 12 & Septicemia ........ & $1.2906(0.050)$ & $1.2388(0.088)$ & $1.0879(0.054)$ & $1.0000(0.103)$ & $1.0000(0.183)$ & $0.0000(0.000)$ \\
\hline 13 & $\ldots \ldots \ldots \ldots \ldots\left({ }^{\star} \mathrm{U} 01-{ }^{\star} \mathrm{U} 02, \mathrm{X} 85-\mathrm{Y} 09, \mathrm{Y} 87.1\right)$ & $1.1200(0.042)$ & $1.3333(0.430)$ & $1.1765(0.171)$ & $1.3372(0.086)$ & $1.3333(0.082)$ & $1.0938(0.109)$ \\
\hline 14 & Essential hypertension and hypertensive renal disease . . . . . . . . . . $(110,|12| 15)$, & $1.2288(0.075)$ & $0.0000(0.000)$ & $1.2500(0.501)$ & $1.4138(0.154)$ & $1.1250(0.117)$ & $1.2162(0.127)$ \\
\hline 15 & Pneumonitis due to solids and liquids. . . . . . . . . . . . . . . . . . . . . . . (J69) & $1.4203(0.114)$ & $1.0000(0.000)$ & $1.2500(0.518)$ & $1.2500(0.201)$ & $1.6800(0.261)$ & $1.3333(0.147)$ \\
\hline$\cdots$ & 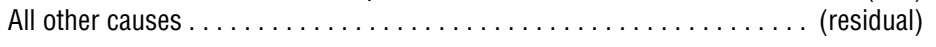 & $1.2992(0.016)$ & $1.1095(0.061)$ & $1.1829(0.036)$ & $1.3834(0.032)$ & $1.2805(0.025)$ & $1.3426(0.043)$ \\
\hline \multicolumn{8}{|c|}{ Male } \\
\hline 1 & $\ldots \ldots \ldots \ldots(100-109,|11| 113,, \mid 20-151)$ & $1.4654(0.027)$ & $0.9000(0.168)$ & $1.2018(0.081)$ & $1.5000(0.043)$ & $1.4849(0.042)$ & $1.4830(0.081)$ \\
\hline 2 & Malignant neoplasms ......... & $1.4448(0.027)$ & $1.4167(0.224)$ & $1.2105(0.119)$ & $1.5134(0.048)$ & $1.4116(0.036)$ & $1.4553(0.090)$ \\
\hline 3 & Accidents (unintentional injuries) $\ldots \ldots \ldots \ldots \ldots \ldots \ldots(\mathrm{V} 01-\mathrm{X} 59, \mathrm{Y} 85-\mathrm{Y} 86)$ & $1.2285(0.023)$ & $1.1244(0.042)$ & $1.1709(0.036)$ & $1.3816(0.053)$ & $1.1981(0.066)$ & $1.3684(0.165)$ \\
\hline 4 & 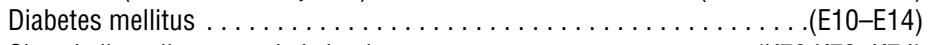 & $1.2046(0.032)$ & $1.0000(0.000)$ & $0.9717(0.043)$ & $1.2325(0.045)$ & $1.1186(0.086)$ & $0.7500(0.237)$ \\
\hline 5 & Chronic liver disease and cirrhosis ..... & $1.1407(0.031)$ & $1.5000(0.707)$ & $1.0556(0.100)$ & $1.1713(0.051)$ & $1.2597(0.048)$ & $1.2286(0.119)$ \\
\hline 6 & Chronic lower respiratory diseases. . . . . . . . . . . . . . . . . . . . . . . (J40-J47) & $1.6298(0.077)$ & $1.0000(0.000)$ & $0.8000(0.322)$ & $1.9322(0.207)$ & $1.5951(0.093)$ & $1.4375(0.184)$ \\
\hline 7 & Intentional self-harm (suicide) ... . . . . . . . . . . . & $1.3253(0.049)$ & $1.0000(0.378)$ & $1.0000(0.156)$ & $1.4314(0.145)$ & $1.3770(0.079)$ & $1.5667(0.210)$ \\
\hline 8 & Cerebrovascular diseases $\ldots \ldots \ldots \ldots \ldots \ldots$ & $1.3864(0.063)$ & $1.0286(0.056)$ & $1.3613(0.073)$ & $1.7119(0.160)$ & $1.8333(0.756)$ & $0.0000(0.000)$ \\
\hline 9 & 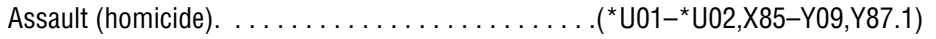 & $1.1180(0.047)$ & $2.0000(1.732)$ & $1.1667(0.189)$ & $1.2889(0.105)$ & $1.3226(0.105)$ & $1.3478(0.161)$ \\
\hline 10 & Nephritis, nephrotic syndrome and nephrosis. . . . . (N00-N07,N17-N19,N25-N27) & $1.3139(0.065)$ & $1.0000(0.522)$ & $1.5000(0.365)$ & $1.2222(0.099)$ & $1.1455(0.078)$ & $1.2121(0.101)$ \\
\hline 11 & Influenza and pneumonia . . . . . . . . . . . . . . . . . . . . . . . . . . . (J09-J18) & $1.1958(0.053)$ & $0.0000(0.000)$ & $0.0000(0.000)$ & $0.0000(0.000)$ & $1.3030(0.163)$ & $1.3500(0.255)$ \\
\hline 12 & Septicemia ............ & $1.3548(0.086)$ & $1.2642(0.104)$ & $1.0822(0.057)$ & $0.9667(0.099)$ & $1.0000(0.302)$ & $0.0000(0.000)$ \\
\hline 13 & Alzheimer disease. . . . . . . . . . . . . . . & $1.3208(0.139)$ & $1.3333(0.444)$ & $1.2500(0.203)$ & $1.4286(0.150)$ & $1.4000(0.146)$ & $0.8571(0.136)$ \\
\hline 14 & Pneumonitis due to solids and liquids. .... & $1.6552(0.223)$ & $0.0000(0.000)$ & $1.3333(0.696)$ & $1.3636(0.152)$ & $1.3750(0.277)$ & $1.0769(0.181)$ \\
\hline 15 & Essential hypertension and hypertensive renal disease ... & $1.2963(0.116)$ & $1.0000(0.000)$ & $1.2500(0.523)$ & $1.2500(0.508)$ & $2.6667(0.758)$ & $1.2222(0.178)$ \\
\hline$\ldots$ & 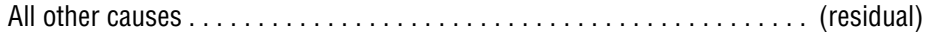 & $1.2992(0.023)$ & $1.1125(0.089)$ & $1.1915(0.049)$ & $1.4324(0.046)$ & $1.2688(0.038)$ & $1.2574(0.066)$ \\
\hline
\end{tabular}


Con.

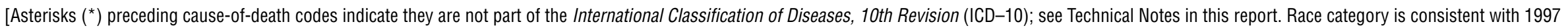
Office of Management and Budget standards]

\begin{tabular}{|c|c|c|c|c|c|c|c|}
\hline \multirow[b]{2}{*}{ Rank $^{1}$} & \multirow{2}{*}{$\begin{array}{l}\qquad \text { Sex and cause of death } \\
\text { (based on International Classification of Diseases, 10th Revision) }\end{array}$} & \multicolumn{6}{|c|}{ Age group (years) } \\
\hline & & All ages ${ }^{2}$ & $0-24$ & $25-44$ & $45-64$ & $65-84$ & 85 and over \\
\hline & Female & & & & & & \\
\hline 1 & $\ldots \ldots \ldots \ldots \ldots \ldots \ldots \ldots(\mathrm{CO0}-\mathrm{C} 97)$ & $1.3618(0.026)$ & $1.2000(0.226)$ & $1.2917(0.112)$ & $1.4556(0.064)$ & $1.3466(0.041)$ & $1.4747(0.060)$ \\
\hline 2 & $\ldots \ldots \ldots \ldots \ldots(100-109,111,|13| 120-151)$, & $1.4051(0.029)$ & $1.1429(0.156)$ & $1.2075(0.119)$ & $1.4165(0.046)$ & $1.3234(0.036)$ & $1.4404(0.099)$ \\
\hline 3 & Accidents (unintentional injuries) ... & $1.2881(0.036)$ & $1.2143(0.079)$ & $1.1379(0.050)$ & $1.5984(0.100)$ & $1.3188(0.088)$ & $1.0333(0.123)$ \\
\hline 4 & Chronic liver disease and cirrhosis . . & $1.1830(0.033)$ & $1.0000(0.000)$ & $1.0933(0.058)$ & $1.2456(0.049)$ & $1.1228(0.072)$ & $1.0000(0.000)$ \\
\hline 5 & Chronic lower respiratory diseases... . & $1.4498(0.063)$ & $0.0000(0.000)$ & $1.0800(0.133)$ & $1.1797(0.050)$ & $1.1262(0.036)$ & $1.1525(0.071)$ \\
\hline 6 & Diabetes mellitus . . . . . . . . . . . . & $1.1432(0.027)$ & $0.0000(0.000)$ & $2.0000(1.091)$ & $1.6625(0.144)$ & $1.3486(0.079)$ & $1.4314(0.133)$ \\
\hline 7 & Cerebrovascular diseases. . & $1.3540(0.050)$ & $1.1667(0.191)$ & $1.1333(0.144)$ & $1.4333(0.123)$ & $1.2879(0.069)$ & $1.4615(0.108)$ \\
\hline 8 & Alzheimer disease. ....... & $1.4018(0.085)$ & $1.1212(0.102)$ & $1.0000(0.109)$ & $1.7500(0.333)$ & $0.5000(0.261)$ & $0.0000(0.000)$ \\
\hline 9 & 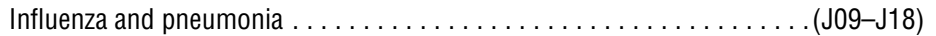 & $1.3510(0.065)$ & $0.0000(0.000)$ & $1.0000(0.000)$ & $1.3529(0.154)$ & $1.2500(0.077)$ & $1.3200(0.196)$ \\
\hline 10 & Nephritis, nephrotic syndrome and nephrosis. .... (N00-N07,N17-N19,N25-N27) & $1.2806(0.066)$ & $1.5000(0.459)$ & $1.1250(0.135)$ & $1.3929(0.164)$ & $1.2931(0.098)$ & $1.4667(0.135)$ \\
\hline 11 & Intentional self-harm (suicide).................... $\left({ }^{*} \mathrm{U} 03, \mathrm{X} 60-\mathrm{X} 84, \mathrm{Y} 87.0\right)$ & $1.1522(0.079)$ & $1.1429(0.155)$ & $0.0000(0.000)$ & $1.0000(0.000)$ & $1.4583(0.134)$ & $1.3710(0.115)$ \\
\hline 12 & 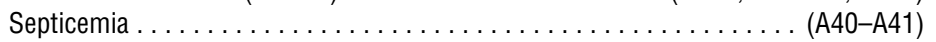 & $1.2482(0.061)$ & $0.0000(0.000)$ & $1.1111(0.145)$ & $1.2500(0.497)$ & $1.0000(0.000)$ & $0.0000(0.000)$ \\
\hline 13 & Essential hypertension and hypertensive renal disease $\ldots \ldots \ldots \ldots \ldots(|10| 12,, \mid 15)$ & $1.1719(0.097)$ & $0.0000(0.000)$ & $1.1111(0.270)$ & $1.2745(0.104)$ & $1.2857(0.095)$ & $1.1600(0.138)$ \\
\hline 14 & Assault (homicide) $\ldots \ldots \ldots \ldots \ldots \ldots \ldots \ldots \ldots \ldots \ldots \ldots \ldots \ldots \ldots$ & $1.1282(0.099)$ & $0.0000(0.000)$ & $1.0000(0.000)$ & $1.5714(0.446)$ & $1.0000(0.118)$ & $1.2917(0.172)$ \\
\hline 15 & 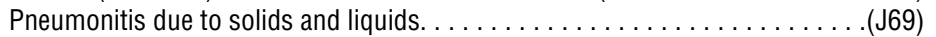 & $1.2500(0.119)$ & $0.0000(0.000)$ & $0.0000(0.000)$ & $1.2500(0.213)$ & $1.1250(0.190)$ & $1.4167(0.226)$ \\
\hline$\ldots$ & 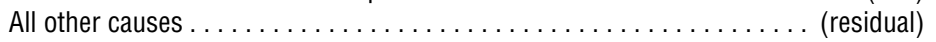 & $1.2993(0.021)$ & $1.1053(0.079)$ & $1.1714(0.054)$ & $1.3288(0.044)$ & $1.2903(0.033)$ & $1.3870(0.055)$ \\
\hline
\end{tabular}

SOURCE: National Center for Health Statistics, National Vital Statistics System, Mortality. 


\section{U.S. DEPARTMENT OF \\ HEALTH \& HUMAN SERVICES}

FIRST CLASS MAIL

Centers for Disease Control and Prevention POSTAGE \& FEES PAID $\mathrm{CDC} / \mathrm{NCHS}$

National Center for Health Statistics

PERMIT NO. G-284

3311 Toledo Road, Room 4551

Hyattsville, MD 20782-2064

OFFICIAL BUSINESS

PENALTY FOR PRIVATE USE, $\$ 300$

For more NCHS NVSRs, visit:

https://www.cdc.gov/nchs/products/nvsr.htm.

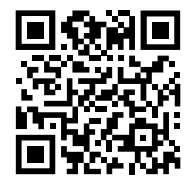

National Vital Statistics Reports, Vol. 70, No. 12, November 9, 2021

\section{Contents}

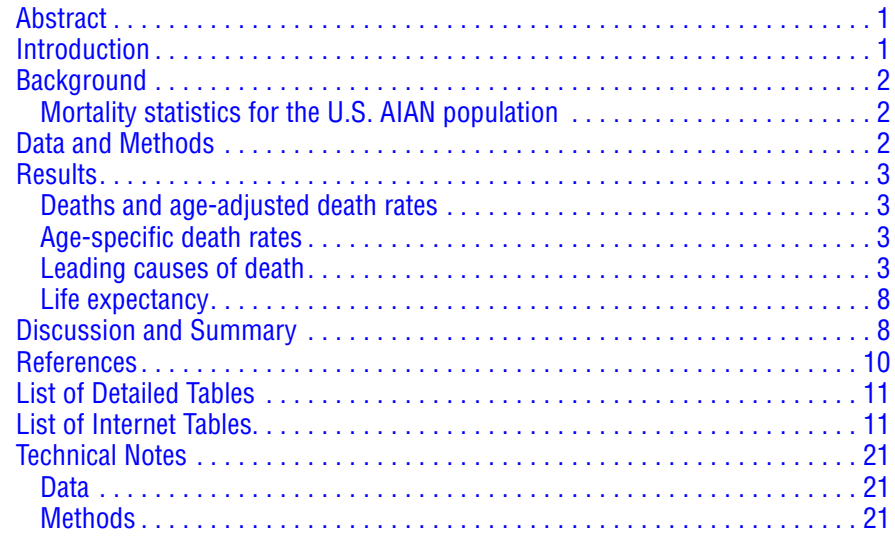

\section{Suggested citation}

Arias E, Xu JQ, Curtin S, Bastian B, TejadaVera B. Mortality profile of the non-Hispanic American Indian or Alaska Native population, 2019. National Vital Statistics Reports; vol 70 no 12. Hyattsville, MD: National Center for Health Statistics. 2021. DOI:

https://dx.doi.org/10.15620/cdc:110370.

\section{Copyright information}

All material appearing in this report is in the public domain and may be reproduced or copied without permission; citation as to source, however, is appreciated.

\section{National Center for Health Statistics}

Brian C. Moyer, Ph.D., Director

Amy M. Branum, Ph.D., Associate Director for Science

Division of Vital Statistics

Steven Schwartz, Ph.D., Director Isabelle Horon, Dr.P.H., Acting Associate Director for Science

For e-mail updates on NCHS publication releases, subscribe online at: https://www.cdc.gov/nchs/email-updates.htm. For questions or general information about NCHS: Tel: 1-800-CDC-INFO (1-800-232-4636) • TTY: 1-888-232-6348 Internet: https://www.cdc.gov/nchs • Online request form: https://www.cdc.gov/info • CS326821 